\title{
Structure and dynamics of the CGRP receptor in apo and peptide-bound forms
}

\author{
Tracy M. Josephs ${ }^{1 *}$, Matthew J. Belousoff ${ }^{1 *}$, Yi-Lynn Liang ${ }^{1 * \dagger}$, Sarah J. Piper'1, Jianjun Cao ${ }^{1}$, Daniel J. \\ Garama $^{2,3}$, Katie Leach ${ }^{1}$, Karen J. Gregory', Arthur Christopoulos ${ }^{1}$, Debbie L. Hay ${ }^{4}$, Radostin Danev ${ }^{5}$., Denise \\ Wootten ${ }^{1}$;, Patrick M. Sexton ${ }^{1}$ *
}

${ }^{1}$ Drug Discovery Biology Theme, Monash Institute of Pharmaceutical Sciences, Monash University, Parkville 3052, Victoria, Australia. ${ }^{2}$ Hudson Institute of Medical Research, Clayton 3168, Victoria, Australia. ${ }^{3}$ Department of Molecular and Translational Science, Monash University, Clayton 3168, Victoria, Australia. ${ }^{4}$ Department of Pharmacology and Toxicology, University of Otago, Dunedin 9054, New Zealand. ${ }^{5}$ Graduate School of Medicine, University of Tokyo, N415, 7-3-1 Hongo, Bunkyo-ku, 113-0033 Tokyo, Japan.

*These authors contributed equally to this work. †Present address: Confo Therapeutics, Technologiepark 94, Ghent (Zwijnaarde) 9052, Belgium. ¥Corresponding author. Email: rado@m.u-tokyo.ac.jp (R.D.); denise.wootten@monash.edu (D.W.); patrick.sexton@monash.edu (P.M.S.)

G protein-coupled receptors (GPCRs) are key regulators of information transmission between cells and organs. Despite this, we have only limited understanding of the behavior of GPCRs in the apo state and the conformational changes upon agonist binding that lead to $G$ protein recruitment and activation. We expressed and purified unmodified apo and peptide-bound calcitonin gene-related peptide (CGRP) receptors to determine their cryo-EM structures and complemented these with analysis of protein conformational dynamics using hydrogen-deuterium exchange mass spectrometry (HDX-MS) and 3D variance analysis of the cryo-EM data. Together with our previously published structure of the active, Gsbound, CGRP receptor complex, our work provides important insight into mechanisms of class B1 GPCR activation.

G protein-coupled receptors (GPCRs) are the most abundant cell surface receptor proteins and among the most important targets for therapeutic drug development (1). They are dynamic proteins that allosterically communicate extracellular signals to the cell interior, engaging with transducer proteins to initiate intracellular signaling cascades (2). Understanding how natural and synthetic ligands bind to GPCRs, and how agonists activate receptors to recruit transducer proteins, is critical to understanding how the body regulates the flow of complex information that is presented to different cells and tissues to enable coordinated biological responses. There has been considerable success in obtaining inactive-state structures bound to inhibitor ligands, in particular by x-ray crystallography of engineered GPCRs $(3,4)$. In addition, advances in cryo-electron microscopy (cryo-EM) have enabled structure determination of active GPCRs in ternary complexes with transducer G proteins or arrestins (3-6).

Despite these advances, understanding of the dynamic molecular processes that enable ligand binding and subsequent receptor activation and G protein recruitment is incomplete, due to the difficulty in elucidating structural information for unmodified receptors in key intermediate states (e.g., apo, agonist-bound). Isolating intermediate states for structure determination has relied on protein engineering to remove mobile domains and to increase receptor thermostability, insertion of fusion proteins, and/or augmentation of the size of the sample with antibodies against the receptor or fusion partners $(3,4)$. Those studies have provided insight into the likely mechanisms of agonist engagement and receptor activation (5-10) but with the caveat that interventions constrain the dynamics of the receptor. We sought to determine the structure of unmodified receptors in the apo state, and in the presence of agonist ligand, but not transducer protein.

The calcitonin gene-related peptide (CGRP) receptor (CGRPR) is the primary target for the actions of the neuropeptide CGRP that has diverse physiological functions including regulation of vascular tone, and modulation of inflammatory and metabolic responses (11). Moreover, CGRP is released under conditions of neurogenic inflammation and is a mediator of migraine pathology, with CGRPR antagonists approved for treatment of migraine (12). The CGRPR is a heterodimer of the class B1 GPCR, calcitonin receptor-like receptor (CLR) and receptor activity-modifying protein 1 (RAMP1), one of three related proteins (RAMP1, RAMP2, RAMP3) (13), with heterodimerization of CLR with RAMP2 or RAMP3 forming distinct adrenomedullin (AM) receptors. We recently reported structures of the active, Gs protein-coupled, complexes of the CGRP and AM receptors $(14,15)$, that revealed a key role for receptor dynamics in RAMP modulation of receptor specificity (15). In the current study, we have used cryoEM to determine the structure of both an apo CGRPR and the 
receptor in the presence of CGRP but not transducer protein. Further, we assessed the dynamics of the apo receptor and how this is altered by CGRP binding using HDX-MS. This was achieved without modification of the target proteins, and thus provides critical information on how these receptors engage with peptide ligand and become activated.

\section{Results and discussion}

Class B1 GPCRs are inherently unstable in detergents leading to poor yields in extraction of native, unmodified receptor proteins from the membrane during solubilization $(16,17)$. However, complexes of GPCRs with heterotrimeric G proteins have much higher stability that have enabled solubilization and purification $(3,4,16,17)$. Most structural work has focused on stabilizing the ternary complex of agonist, GPCR and $\mathrm{G}$ protein through removal of guanine nucleotides, mutations within the $\mathrm{G} \alpha$ protein or the use of nanobodies or antibodies to reduce disassembly of the $\mathrm{G} \alpha-\mathrm{G} \beta \gamma$ heterotrimer and stabilize interactions within the $\mathrm{G}$ protein $(3-6,14-17)$. There are reports that GPCRs and G proteins preassemble, as early as the ER, in non-signaling complexes $(18,19)$ that likely facilitate fidelity of receptor folding. We hypothesized that such preassembly of a non-functional GPCR:G protein complex may enable robust expression and purification of apo CGRPRs or complexes of the receptor bound to agonist peptide in the absence of $\mathrm{G}$ protein. In this case we utilized a modified $G \alpha_{11}$ protein, which enabled the purification of apo CGRP receptor in reasonable yields that were not achieved in the absence of $\mathrm{G}_{11}$.

\section{Structure determination}

Epitope-tagged CLR and RAMP1 constructs previously used to determine the structure of the active CGRPR:CGRP:Gs complex (14) were co-expressed with a modified $\mathrm{G}_{11}$, HisGß1, G $\curlyvee 2$ and Ric8A in Trichoplusia ni insect cells. Cell pellets, in the absence or presence of either $1 \mu \mathrm{M}$ or $10 \mu \mathrm{M}$ CGRP, were solubilized in LMNG/cholesteryl hemisuccinate and subjected to 3C cleavage of the CLR tags and anti-FLAG chromatography and SEC to yield monodisperse peaks containing CLR and RAMP1 as confirmed by SDS-PAGE (fig. S1, A to D). Aliquots of the purified protein were subsequently used for either cryo-EM determination of structure or analysis of structural dynamics by HDX-MS.

Vitrified samples were imaged in single particle cryo-EM on a Titan Krios microscope with initial 2D classification revealing particle classes with high-resolution secondary structural features (fig. S1, E and G). These were subsequently subjected to $3 \mathrm{D}$ classification using the particle polishing and CTF refinement routines in RELION 3.1 (20). Refined particles were imported into cryoSPARC v2.9 $(21,22)$ and subjected to the non-uniform $3 \mathrm{D}$ refinement to yield $3 \mathrm{D}$ consensus density maps with global resolutions (FSC 0.143) of $3.15 \AA$ for the apo receptor (Fig. 1A, fig. S1F, and table S1) and $3.49 \AA$ for the receptor in complex with CGRP (Fig. 1C, fig. $\mathrm{S} 1 \mathrm{H}$, and table $\mathrm{S} 1$ ). Additional $3 \mathrm{D}$ maps were calculated using the local noise filtering routines implemented in SIDESplitter (23) in combination with a RELION maximumlikelihood 3D-refinement to aid model building and increase model confidence; maps calculated in both software packages had very high similarity. Although the density was of varying resolution (Fig. 1, A and C), it was sufficient to enable modelling of the backbone of most of the receptor and RAMP1 (Fig. 1, B and D); with the exception of 55-63 and 107-109 of the CLR extracellular domain (ECD), intracellular loop (ICL) 3 (ICL3) 320-328 and extracellular loop (ECL) 3 (ECL3) 355362 . No robust density was observed beyond amino acid 402 of the CLR $\mathrm{C}$ terminus or 142 of the RAMP1 $\mathrm{C}$ terminus. In the CGRP-bound structure, only density for the $\mathrm{C}$ terminus (27-37) of the peptide was resolved in the consensus map (Fig. 1D). The peptide resolution was insufficient to enable robust modelling of side chains, however the main chain could be modeled (fig. S2). Similarly, the density of the ECDs of RAMP1 and CLR, and the TMD-ECD linker region of RAMP1, were of lower resolution than the rest of the map and did not allow confident assignment of amino acid side chains (fig. S2). As such, comparisons between structures for these domains is limited to the protein backbone. For most of the TM helices, ICL1, ECL1, ICL2 and ECL2 there was density enabling modelling of amino acid side chains (fig. S2). For the CGRP-bound structure, the lower third of TMs 5 and 6 had lower resolution compared to the Apo structure (fig. S2).

\section{Comparison of Apo, CGRP-bound and CGRP-and Gs protein-bound CGRP receptors}

The apo and CGRP-bound structures of the CGRPR provide key initial and intermediate states in the activation of CGRPRs that complement our previously published structure of the active-state, G protein-bound receptor (14) to enable us to interrogate the process of receptor activation. Crucially, the proteins in our study are unmodified except for purification tags and maintain wild-type pharmacology (14).

Both the apo and CGRP-bound CGRPRs lack the key hallmark features of activated class B1 GPCRs, including the outward movement of TM5/TM6/ICL3 to accommodate G protein binding (24-26), with a relatively straight TM6, and where the base of both TM5 and TM6 is packed closely with TMs 2, 4 and 7, and ICL2. In the consensus structures, the intracellular face of both the apo and peptide bound receptors are very similar (Fig. 2A). In the apo receptor, conserved polar residues that are implicated in maintenance of an inactive state in class B1 GPCRs (27-29), including R173.46, $\mathrm{H} 177^{2.50}$, E233 ${ }^{3.50}$, and $\mathrm{T} 338^{6.42}$ [superscript numbers refer to the Wootten et al., class B1 numbering system, $(30,31)]$, are oriented toward each other and may participate in $\mathrm{H}$-bond 
interactions either directly or via structural waters (fig. S3A). Alanine mutagenesis of $\mathrm{R} 173^{2.46}$ or $\mathrm{H}^{2} 77^{2.50}$ support the importance of these residues in CGRPR function, while there is only limited effect with mutation of either E233.5.50 or T338 $8^{6.42}$ (29). Additional networks are observed that stabilize the ICL2 conformation in an inactive state, involving $\mathrm{H}$-bond interactions between $\mathrm{Q} 172^{2.45}$ and the backbone of Q250 $0^{4.40}, \mathrm{Y}^{236^{3.53}}$ and $\mathrm{Q}_{172^{2.45}}$ (not displayed), and between $\mathrm{Cl}^{2} 1^{2.44}$ and E248 $8^{\text {ICL2 }}$. This network also contributes to the location of R173 ${ }^{2.46}$ enabling participation in the conserved network described above. The sidechains of N388 ${ }^{7.61}$ at the base of TM7 and $\mathrm{Q} 392^{8.43}$ at the proximal end of helix 8 form weak Hbonds with the backbone of F384 ${ }^{7.57}$ and F386 $6^{7.59}$, respectively, and contribute to stabilization of the bottom of TM7, while $\mathrm{N} 388^{7.61}$ could also potentially form a water-mediated interaction with $\mathrm{R} 173^{2.46}$. Alanine mutagenesis of N $388^{7.61}$ leads to a 10-fold reduction in CGRP potency, supporting the importance of side-chain interactions for this residue (29). Collectively, these polar networks enable the apo CGRPR to maintain an inactive state and are reorganized in the Gs- and CGRP- bound active receptor (fig. S3, B, D, and F), where a number of these side chains form direct interactions with the Gs protein (14).

At the extracellular face of the receptor, TM6 and to a lesser extent TM7 are closer to the core of the TM bundle in both structures, partially overlapping with the location of the peptide binding pocket in the active receptor (Fig. 2, B and C). Consistent with this, density for the $\mathrm{N}$ terminus of CGRP could not be resolved in the map of the peptide bound receptor. Nonetheless, the extracellular face of the receptor was open in both cases with pocket volumes for the apo and CGRP-bound receptors of 3928 and $4269 \AA^{3}$, respectively (Fig. $2 \mathrm{~A}$ and fig. S4, A and B). In the fully active, Gs coupled receptor where the $\mathrm{N}$ terminus of the peptide is bound, the pocket is expanded, with a volume of $5280 \AA^{3}$ (fig. S4C) (14). This suggests that access to the pocket requires dynamic motion in the TM bundle that is limited in the absence of the G protein.

At a backbone level, the apo and CGRP-bound CGRPR structures were almost identical, with the most robust differences observed in the relative position of the RAMP1 ECD (Fig. 2A, arrow), and its most C-terminally resolved TM residues [Fig. 2A, inset (blue)], with an additional small difference in the TM2 proximal segment of ECL1 of the CLR [Fig. 2A, inset (red)]. However, the position of the receptor ECD relative to the core was very similar both between the apo and CGRP-bound structures and between these structures and the fully active complex of the receptor with $\mathrm{G}$ protein (Fig. 2, A to C, and movie S1). This contrasts markedly with the proposed dynamics of the ECD in the activation of other, non-calcitonin family, class B1 GPCRs such as the glucagonlike peptide-1 receptor (GLP-1R) (Fig. 2D) (32). Nonetheless, a number of important differences could be observed between the apo and peptide bound static structures that provide insight into the activation process. In the apo receptor, the RAMP1 TM-ECD linker is more weakly engaged with residues in ECL2/TM5 of CLR than the corresponding CGRPbound receptor; in particular, $\mathrm{D} 113^{\mathrm{R} 1}$ in the apo receptor forms weaker interactions with ECL2 (Fig. 3A). D113 ${ }^{\mathrm{R} 1}$ is rotated toward ECL2 in the CGRP-bound structure where it likely promotes H-bonding with T288 ${ }^{\mathrm{ECL} 2}$ (Fig. 3, A and B). While alanine mutation of $\mathrm{D}_{113^{\mathrm{R} 1}}$ alone has a weak impact on CGRP, mutation of T288 $8^{\mathrm{ECL} 2}$ causes an $\sim 25$-fold reduction in peptide potency $(33,34)$ and this is consistent with the importance of the dynamics of interaction between the RAMP linker and ECL2 in CLR-based receptor (15). This in turn is associated with shifts in the rotameric position of Y292 $2^{5.37}$ and $\mathrm{H} 289^{5.34}$ that become aligned with their position in the fully active structure (Fig. 3, A and B), suggesting that this may be an important event that occurs before $\mathrm{G}$ protein engagement. Nonetheless, alanine mutation of either of these residues alone did not affect CGRP potency, indicating that they are not critical for signaling (34). This change in the interaction of the RAMP1 linker and ECL2 of CLR is likely facilitated by the stabilization of the ECD following binding of the CGRP C terminus that could contribute to the subtle difference in ECD backbone position between apo and peptide-bound structures (Fig. 2A).

Comparing the CGRP-bound and CGRP- and G proteinbound structures reveals the key changes to receptor structure that are facilitated principally by G protein binding in the fully active complex. At the extracellular face, the most dramatic changes are in the tops of TM1, TM6 and TM7/ECL3 (Fig. 3C). The largest change is in TM6 that adopts a sharp kink outward in parallel with the outward movement at its base (Fig. 3, C and D, and fig. S3, A and B). This kink within TM6 is associated with twisting around the $\mathrm{P}^{6.47} \mathrm{XXG}^{6.50}$ within the center of the helix that results in a register shift in the helix, when comparing the CGRP-bound and the CGRPand Gs- bound structures (movie S1). Given the overlap in TM1 structure between the apo and CGRP-bound receptors, it is likely that changes in TM1 are facilitated by the movement of TM7 that occur on transducer engagement. While changes to side chain orientation at the top of TM5/ECL2 are principally driven by peptide binding, there is an upward movement of ECL2 associated with G protein binding (Fig. $3 \mathrm{C}$ and movie $\mathrm{S} 1$ ) that has previously been suggested to occur with activation of other class B1 GPCRs (24). At the intracellular face, the kink in TM6 leads to a 16.4 $\AA$ outward movement of the base of TM6 (measured from the C $\alpha$ of $\mathrm{L}_{330^{6.34}}$ ), with a corresponding $4.9 \AA$ outward movement of the base of TM5 (measured from the $\mathrm{C} \alpha$ of T318 ${ }^{5.63}$; movie S1), and lateral movement of TM3 by $4.3 \AA$ (measured from the $\mathrm{C} \alpha$ of V243 $3^{3.60}$; Fig. 3D). This in turn is associated with changes in 
the conformation of ICL2, including the orientation of F246 $6^{\text {ICL2 }}$ to position it into the junction of the $\alpha 5$ and $\alpha \mathrm{N}$ helices of Gs in the active receptor (Fig. 3D and fig. S3, C and D). Equivalently positioned aromatic residues within ICL2 have been observed in many Gs-coupled receptor structures and are implicated in Gs activation $(24,25,35,36)$. Finally, there are also differences in the base of TM7 that are linked to the location of the C-terminal helix 8, in particular, loss of $\mathrm{H}$ bonding of $\mathrm{N} 388^{7.61}$ and Q392 ${ }^{8.43}$ with the backbone of TM7 is observed in the fully-active structure (Fig. 2B; Fig. 3E; and fig. S3, E and F).

Within the receptor core, there is reorganization of the conserved central polar network in class B1 GPCRs, comprising $\mathrm{N} 187^{2.60}$, N226 $6^{3.43}$, E348 $8^{6.52}$ and $\mathrm{Q} 376^{7.49}$; in particular, large movements occur in the location of E348 ${ }^{6.52}$ and Q376 $6^{7.49}$ (Fig. 3, E to G; fig. S3, G and H; fig. S5; and movies S1 and S2), as well as in the packing of F349 $9^{6.53}$, Y227 $7^{3.44}$ and M230 $30^{3.47}$ that accompany the large conformation changes required for $G$ protein coupling (Fig. 3, E to G; fig. S3, G and H; fig. S5; and movies $\mathrm{S} 1$ and $\mathrm{S} 2$ ), albeit that mutation of individual residues has only limited effect on CGRP potency $(29,37)$. This network is also coordinated with additional polar residues at $\mathrm{T}_{191^{2.64}}$ and $\mathrm{H} 219^{3.36}$ that form $\mathrm{H}$-bonds with $\mathrm{N} 187^{2.60}$ in the apo structure. These amino acids are important for peptide binding in many class B1 GPCRs (24), and their mutation in the CGRPR reduces peptide potency $(29,38)$.

\section{Dynamics of Apo and CGRP-bound CGRP receptors}

Despite the insights possible through examination of static structures, GPCRs are dynamic proteins and ligand binding and activation can only be understood through consideration of the dynamics of the protein as it transitions from apo to ligand-bound forms. This is clear in the current study where information on how the peptide $\mathrm{N}$ terminus interacts with the receptor to allosterically modulate the intracellular face and facilitate $G$ protein engagement is not evident in the static structures. To address this, we performed HDX-MS analysis of the apo and peptide-bound receptors using the same preparations used for structure determination, as well as on an independent preparation for the CGRP-bound receptor, with consistent results (Fig. 4, figs. S6 to S9, and data S1). In parallel, we performed $3 \mathrm{D}$ variance analysis of the cryoEM data to collectively derive insight into how receptor dynamics are altered by CGRP binding.

In the apo state, HDX-MS analysis over time demonstrated that the RAMP1 ECD, extending through the linker to the top of the TM helix, had rapid exchange illustrative of relatively high conformational dynamics (Fig. 4, A and C, i and ii; fig. S9; and data S1). Most of the RAMP1 TM exhibited only limited HDX, however, the far $\mathrm{C}$ terminus exhibited rapid exchange (Fig. 4C, iii). Binding of CGRP led to substantial decreases in HDX for most of the RAMP (Fig. 4, A and C), with the exception of the VGETL loop between ECD helices 1 and 2 (Fig. $4 \mathrm{C}$, i). While there was reduced exchange, the TM $\mathrm{C}$ terminus also remained mobile in the peptide-bound sample (Fig. 4C, iii). The CLR protomer in the apo sample was highly dynamic, with greatest HDX observed for the ECD, top of TM1, the extracellular and intracellular loops, and the $\mathrm{C}$ terminus of helix 8 (Fig. 4C, iv to viii; fig. S8; and data S1). There was also substantial exchange for the top of TM3 and the intracellular half of TM6 (fig. S8 and data S1). In the CGRP-bound sample, while CLR remained highly dynamic, there was overall reduced exchange at the earlier time points. At later time points, there was increased HDX at the base of TM6 in presence of the peptide suggestive of allosteric effects of CGRP binding that might facilitate $\mathrm{G}$ protein binding (fig. S8 and data $\mathrm{S} 1)$.

The HDX data correlated well with the observations of dynamics in the Cryosparc 3D variance analysis of the cryo-EM data, with regions that exhibit highest HDX having the greatest mobility in all three principal components of the analysis, including greater motions within the ECD for the apo versus CGRP-bound data (movie S3). For the CGRP-bound data, density for the peptide $\mathrm{C}$ terminus was present in all maps, however, it was relatively poorly resolved in most cases, indicative of instability of interactions with the receptor (Fig. 5, A and $\mathrm{B}$, and movie S4). In both apo and CGRP-bound analyses, ECL1 that has high rates of HDX, undergoes movements that increase or decrease the distance to TM1 that are likely important for the peptide $\mathrm{N}$ terminus to be able to enter into the core of the receptor (movie S4). Parsing of the 3D data along vectors of motion also revealed 2 key facets of the CGRP-bound structure that were not evident in the consensus map. In all 3 principal components, the receptor transitions from density maps that lack signal for the peptide $\mathrm{N}$ terminus to maps where this density is clearly discernible, and which is in equivalent position to the location of the peptide $\mathrm{N}$ terminus in the active structure; no density in this region is observed in any of the maps of the apo receptor structure (Fig. 5C and movie S4). This is primarily enabled by changes to the top of TM6 (although it does not appear to undergo the extent of outward movement present in the fully activated receptor) (movie S4), and is correlated with greater density for interaction between the RAMP1 linker and ECL2 that is likely linked to stability of H-bonding that was observed in the static map for the peptide-bound complex (Fig. 5 and movie S4). At the intracellular face of the receptor, the conformations within the trajectories where the peptide $\mathrm{N}$ terminus become visible exhibit decreased interactions between TM6 and TM2 that are likely important to facilitating G protein engagement (Fig. 6A); these are likely the initiating events for the reorganization of the conserved polar networks at the base of the receptor described above. In contrast, while there is motion of the intracellular face of the receptor in the 
apo state, TM6/TM5/ICL3 maintain interactions with the rest of the receptor for each of the principal components (Fig. 6B).

\section{A modelfor CGRP binding and activation of the CGRPR}

Collectively, our data allow understanding of key elements of the binding and activation mechanism for the CGRPR (Fig. 7). In the apo state, the receptor ECD has a comparatively stable position relative to the receptor core, with the TM bundle having an open conformation at the extracellular face that creates a wide cavity for ligand engagement. In this state, both the RAMP1 and CLR ECD are relatively dynamic, allowing the receptor to adopt conformations that facilitate binding of the peptide $\mathrm{C}$ terminus (amino acids 27-37). The apo receptor also exhibits conformational dynamics within the CLR extracellular loops and top of TM1 that allow the peptide $\mathrm{N}$ terminus to enter the receptor core, and facilitate conformational transitions required for binding of the peptide $\mathrm{N}$ terminus deep within the TM cavity. The intracellular loops are also dynamic and facilitate the conformational changes required for interaction with transducer proteins. Binding of the peptide $\mathrm{C}$ terminus stabilizes the $\mathrm{ECD}$, in particular that of RAMP1 that in turn reduces the motion of the linker region between the RAMP1 ECD and TM, which facilitates H-bonding with ECL2 of the CLR protomer and initial conformational changes within the CLR bundle that facilitate binding of the peptide $\mathrm{N}$ terminus. In the absence of $\mathrm{G}$ protein, the peptide $\mathrm{N}$ terminus forms only weak and transient interactions with the TM bundle and is highly dynamic. However, when the $\mathrm{N}$ terminus is engaged, there is a weakening of intracellular interactions within the receptor that otherwise help maintain TM6/TM5/ICL3 in an inactive conformation, and which in turn facilitate engagement with G protein. This may also release constraints on ICL2 that allow conformational reorganization and hydrophobic interaction with the G protein $\alpha \mathrm{N} / \alpha 5$ junction. G protein binding triggers the larger conformational change that is stabilized in the fully active receptor conformation, including kinking of TM6, outward movement of TM5 and changes at the base of TM7 that are propagated to the extracellular face and are associated with a further kinking and outward movement of TM6, outward movement of TM7, changes in the conformation of TM1, and general upward movement of ECL2 that facilitate stable engagement of the peptide- $\mathrm{N}$ terminus within the TM binding cavity (Fig. 7).

\section{Implications for activation of class B1 GPCRs}

The intracellular changes to the CGRPR as it transitions from an apo state to activated, G protein-bound state, are likely conserved with other class B1 GPCRs consistent with the secondary structural features that are in common among the active-state receptors solved to date $(24,25,27)$. Among the most conserved residues in class B1 GPCRs are those involved in key interactions of the apo state CGRPR. These include the absolutely conserved amino acids, R173 ${ }^{2.46}$, E233 $3^{3.50}$, H177 2.50 and $\mathrm{T} 338^{6.42}$ that comprise the polar network at the base of the receptor in the apo state (fig. S10). Mutation of the latter 2 residues reduces the barrier to active state transition and can lead to constitutive activity in some class B1 GPCRs, including for the glucagon and PTH1 receptors $(39,40)$, with natural polymorphic variants of the PTH1R leading to Jansen's metaphyseal chondrodysplasia (40). Similarly, $\mathrm{C} 171^{\mathrm{ICL} / 2.44}$ and $\mathrm{E} 248^{\mathrm{ICL} 2}$ that contribute to maintenance of the inactive conformation of ICL2, and $\mathrm{N} 388^{7.61}$ and $\mathrm{Q} 392^{8.43}$ at the base of TM7/H8 are also very highly conserved (fig. S10). Interestingly, although these latter residues H-bond to the backbone of TM7 in the apo structure, the sidechains are conserved; Phe is found at these positions in TM7 across all class B1 GPCRs consistent with importance of the packing of TM7 in both inactive and active states. Within the core of the receptor, polar residues at positions 2.60 (N187), 3.43 (N226), 6.52 (E348) and 7.49 (Q376) (fig. S10) that are recognized as important for class B1 receptor activation and biased agonism $(27,30)$ contribute to packing of the receptor in the apo state. $\mathrm{N} 226^{3.43}$ forms a H-bond with the conserved S183 $3^{2.56}$ and contributes to the location and packing of Y227.44 and M230 ${ }^{3.47}$, while Q376 $6^{7.49}$ provides further coordination for the location of Y2273.44. While no direct H-bonds are formed by E $348^{6.52}$ in the apo state, there are likely water-mediated $\mathrm{H}$ bonds to other residues of the central polar network that help stabilize TM6 in an inactive conformation, including packing of F34. $9^{6.53}$ with Y22 $7^{3.44}$. The conserved aromatic/large hydrophobic residues at positions $3.44,3.47$ and 6.53 in the core of the receptor undergo some of the largest changes during receptor activation and mutation of these residues in class B1 GPCRs provides support for their critical role in receptor activation $(27,30)$.

In the glucagon subfamily of class B1 GPCRs, interactions of the receptor ECD and ECLs are predicted to help maintain an inactive receptor state, with evidence supporting the importance of interaction between the far $\mathrm{N}$ terminus of the glucagon receptor ECD and ECL3 in receptor quiescence $(41,42)$. The recent, full length, inactive state structure of GLP-1R (43) provided structural evidence to support this interaction (Fig. $2 \mathrm{D}$ ), and release of this interaction upon peptide binding to the ECD is believed to contribute to increased dynamics of ECL3 that enable engagement of the peptide $\mathrm{N}$ terminus and recruitment of G protein (32). While the CGRPR exists in a more open conformation in the apo state, initial binding also occurs between the peptide $\mathrm{C}$ terminus and ECD leading to transient interactions between the peptide $\mathrm{N}$ terminus and receptor core that can be observed in extremes of the conformational ensembles in 3D variability analysis (Fig. 5 and movie S4). In the absence of G protein, however, the engagement of the peptide $\mathrm{N}$ terminus does not induce large 
conformational changes to the intracellular face of the receptor, rather there is a weakening of ground state interactions and increased mobility of the intracellular ends of the TMs. This is likely true for all class B1 GPCRs; initial transient interactions with the peptide facilitate $\mathrm{G}$ protein binding, but interaction with the $\mathrm{G}$ protein is required for the larger conformational changes that stabilize interactions of the N-terminal activation domain of the peptides with the receptor core (Fig. 7). Further work, including additional structures of intermediate states of class B1 GPCRs combined with biophysical measures of conformational dynamics and molecular dynamics simulations of structures in different states, will be required to broaden our understanding of receptor activation. Nonetheless, the proposed model of class B1 GPCR activation is consistent with the observations for other classes of GPCRs, including the more extensively studied class A GPCRs where biophysical studies have demonstrated that binding of agonist or $\mathrm{G}$ protein alone is insufficient to recapitulate the conformation of the fully active, agonist and transducerbound receptors (9).

Collectively, our work provides important understanding of both the apo state of class B1 GPCRs and the mechanisms of receptor activation. The use of essentially unmodified receptor allowed us to gain insight into the changes to conformational dynamics that occur upon agonist binding by complementary implementation of cryo-EM and HDX-MS.

\section{Materials and methods}

\section{Constructs}

CLR and RAMP1 constructs used were previously reported (14). Specifically, CLR contained an 3C protease cleavable Nterminal Flag tag epitope and a C-terminal 8 histidine tag. RAMP1 contained an N-terminal Flag tag epitope and to improve expression, a hemagglutinin signaling peptide replaced the natural signal peptide in both the CLR and RAMP1 constructs. A mutant form of $\mathrm{G} \alpha_{11}$ protein designed to reduce nucleotide binding and stabilize interactions with the $\beta$ subunit, containing S53N, G208A, E250A, A253K, R256D, P262K, S267D, S268T, A331S substitutions was also generated to help expression and purification of detergent solubilized receptors. This $\mathrm{G}$ protein did not form stable interactions with the receptor, enabling purification of the apo CGRPR.

\section{Insect cell expression}

CLR, RAMP1, mutant $\mathrm{G}_{11}$ and Ric8-A were co-expressed in Trichoplusia $n i$ insect cells (Expression systems) using baculovirus. Cells were grown to a density of $4 \mathrm{M}$ cells $/ \mathrm{mL}$ in ESF 921 serum-free media (Expression Systems) before transfection with separate baculoviruses. Culture was harvested by centrifugation 48 hours post infection and cell pellet was stored at $-80^{\prime} \mathrm{C}$.

\section{Complex purification}

CLR and RAMP1 containing cell pellets were thawed in 20 $\mathrm{mM}$ HEPES pH 7.4, $100 \mathrm{mM} \mathrm{NaCl}, 2 \mathrm{mM} \mathrm{MgCl}_{2}$ and $3 \mathrm{mM}$ $\mathrm{CaCl}_{2}$ supplemented with cOmplete Protease Inhibitor Cocktail tablets, Benzonase (37.5 U/mL, Merck Millipore) and 3C protease $(10 \mu \mathrm{g} / \mathrm{mL}$; to cleave tags from CLR), with or without either $1 \mu \mathrm{M}$ or $10 \mu \mathrm{M}$ of CGRP (Chinapeptides). Lauryl maltose neopentyl glycol (LMNG, Anatrace) and cholesteryl hemisuccinate (CHS, Anatrace) were added to a final concentration of $0.5 \%$ and $0.03 \%$, respectively and detergent solubilization occurred over 1 hour at $4^{\circ} \mathrm{C}$. Insoluble material was removed by centrifugation at 30,000 $\mathrm{x} g$ for $15 \mathrm{~min}$ and the solubilized complex was immobilized by batch binding to M1 anti-Flag affinity resin (prepared in-house) for 2 hours at room temperature. The resin was packed into a glass column and washed with 20 column volumes of $20 \mathrm{mM}$ HEPES pH 7.4, $100 \mathrm{mM} \mathrm{NaCl}, 2 \mathrm{mM} \mathrm{MgCl}, 3 \mathrm{mM} \mathrm{CaCl}_{2}, 0.01 \%$ (w/v) LMNG and $0.0006 \%(\mathrm{w} / \mathrm{v}) \mathrm{CHS}$, with or without $1 \mu \mathrm{M}$ CGRP, before bound material was eluted using a calcium-free buffer (20 mM HEPES pH 7.4, $100 \mathrm{mM} \mathrm{NaCl}, 2 \mathrm{mM} \mathrm{MgCl} 2,10 \mathrm{mM}$ EGTA, with or without $1 \mu \mathrm{M}$ CGRP, 0.01\% (w/v) LMNG and $0.0006 \%(\mathrm{w} / \mathrm{v}) \mathrm{CHS}$ ) containing $0.2 \mathrm{mg} / \mathrm{mL}$ Flag peptide. The complex was concentrated using an Amicon Ultra Centrifugal Filter (MWCO $100 \mathrm{kDa}$ ) and subjected to size-exclusion chromatography on a Superdex 200 Increase 10/300 column (GE Healthcare) that was pre-equilibrated with $20 \mathrm{mM}$ HEPES $\mathrm{pH} 7.4,100 \mathrm{mM} \mathrm{NaCl}, 2 \mathrm{mM} \mathrm{MgCl}$, with or without $80 \mu \mathrm{M}$ CGRP (to ensure high receptor occupancy), $0.01 \%$ (w/v) LMNG and $0.0006 \%(\mathrm{w} / \mathrm{v})$ CHS. Eluted fractions corresponding to the apo and CGRP bound complex were pooled and concentrated. Final yield of purified complex was approximately $0.7 \mathrm{mg} / \mathrm{L}$ of insect cell culture.

\section{Vitrified sample preparation and data collection}

Samples $(3 \mu \mathrm{L})$ were applied to a glow-discharged UltrAuFoil R1.2/1.3 300 mesh holey carbon grid (Quantifoil GmbH, Großlöbichau, Germany) and were flash frozen in liquid ethane using the Vitrobot mark IV (Thermo Fisher Scientific, Waltham, Massachusetts, USA) set at $100 \%$ humidity and $4{ }^{\circ} \mathrm{C}$ for the prep chamber. Data were collected on a Titan Krios G3i microscope (Thermo Fisher Scientific) operated at an accelerating voltage of $300 \mathrm{kV}$ with a $50 \mu \mathrm{m} \mathrm{C} 2$ aperture at an indicated magnification of $105 \mathrm{~K}$ in nanoprobe EFTEM mode. A Gatan K3 direct electron detector positioned post a Gatan Quantum energy filter (Gatan, Pleasanton, California, USA), operated in a zero-energy-loss mode with a slit width of $25 \mathrm{eV}$ was used to acquire dose fractionated movies of the samples with a $100 \mu \mathrm{m}$ objective aperture. The camera was operated in correlated double sampling (CDS) mode. Movies were recorded in hardware-binned mode yielding a physical pixel size of $0.83 \AA /$ pix with an exposure time of 5.011 and $7.2 \mathrm{~s}$ amounting to a total exposure of 57.3 and $52.4 \mathrm{e}-/ \AA^{2}$ at an exposure 
rate of 7.9 and $7.2 \mathrm{e}-/ \mathrm{pixel} / \mathrm{second}$ for the apo and CGRP bound receptors, respectively, which were fractionated into 71 subframes. Defocus range was set between -0.6 to $-1.5 \mu \mathrm{m}$. A total of 5634 and 5598 movies were collected for the apo and CGRP bound receptors.

\section{Cryo-EM data processing}

5364 and 5598 movies of apo CGRPR and CGRP-bound $C G R P R$ were motion corrected using motion correction2 (44) and their CTF parameters were estimated using CTFFIND 4.1 (45). Particles were picked from corrected micrographs using the Laplacian of Gaussian picker as implemented in RELION 3.1 (20). Picked particles (4.51 M and 4.59 M particles of apo CGRPR and CGRP-bound CGRPR) were extracted using a box size of 64 pixels and 2D classified using RELION (version 3.1). The selected 2D particles (1.46 M and $1.98 \mathrm{M}$ particles of apo CGRPR and CGRP-bound CGRPR) were used in initial 3D classification. An initial 3D model was generated by modifying the map from the published CGRPR structure (PDB: 6E3Y), where the density from the G proteins was manually erased and the resultant map was re-centered in a 240 pixel box and a low pass filter of $40 \AA$ was applied. This model was then used in a single class 3D classification in RELION 3.1 where the maximum likelihood $\tau$ value was tuned until a reasonable 3D model was generated and then these angular priors were used for 3D refinement. The resulting particles were then subjected to Bayesian particle polishing and exported into cryoSPARC v2.9 (21) where they underwent further 2D classification and non-uniform 3D refinement (22), resulting in maps resolved to $3.15 \AA$ and $3.49 \AA$ for the apo CGRPR and $C G R P$-bound CGRPR, respectively ( $\mathrm{FSC}=0.143$ ) (fig. $\mathrm{S} 1, \mathrm{~F}$ and $\mathrm{H})$. Using the same particle stack as used in the non-uniform refinement, a local noise filtered refinement was carried out in RELION 3.1 with the maximization step performed by SIDESplitter (23). The global resolutions for these refinements were calculated at $3.21 \AA$ and $3.55 \AA$ for the apo CGRPR and CGRP-bound CGRPR, respectively $(\mathrm{FSC}=0.143)$. These maps were used to aid atomic model building. The dip in the FSC curves at lower resolution is a consequence of the distinct resolution characteristics of the detergent micelle at those wavenumbers. The selected particles were also used for the 3D-Variabiliy analysis as implemented in cryoSPARC.

\section{Atomic model refinement}

The model of the receptor portion of CGRP:CGRPR-Gs (PDB: 6E3Y) used as initial template was fitted in the cryo-EM density maps in UCSF Chimera (v1.14) (46), followed by molecular dynamics flexible fitting (MDFF) simulation with nanoscale molecular dynamics (NAMD) (47). The fitted model was further refined by rounds of manual model building in COOT (48) and real space refinement, as implemented in the Phenix software package (49).

\section{HDX-MS methods}

HDX-MS was performed using an ACQUITY UPLC ${ }^{\circledR}$ M-Class System with automated HDX Technology and SYNAPT G2 Si HDMS Mass Spectrometer (Waters, Milford, MA, USA). Continuous labeling deuterium exchange was initiated by mixing $3 \mu \mathrm{L}$ of apo CGRPR and CGRP-bound CGRPR with $57 \mu \mathrm{L}$ of $\mathrm{D}_{2} \mathrm{O}$ buffer (20 mM HEPES pH 7.4, $100 \mathrm{mM} \mathrm{NaCl}, 2 \mathrm{mM}$ $\mathrm{MgCl} 2$, with or without $80 \mu \mathrm{M}$ CGRP, $0.01 \%$ (w/v) LMNG and $0.0006 \%(\mathrm{w} / \mathrm{v}) \mathrm{CHS}$ ) and incubated for 0.5, 1, 10, 100, $200 \mathrm{~min}$ at $20^{\circ} \mathrm{C}$. Deuterated samples $(50 \mu \mathrm{L})$ were quenched using 50 $\mu \mathrm{L}$ of ice-cold quench buffer $\left[10 \mathrm{mM} \mathrm{K} \mathrm{K}_{2} \mathrm{HPO}_{4} / \mathrm{KH}_{2} \mathrm{PO}_{4}, 2 \mathrm{M}\right.$ guanidine $\mathrm{HCl}, 200 \mathrm{mM}$ TCEP ( $\mathrm{pH}$ 2.3)]. Non-deuterated samples were prepared by mixing $3 \mu \mathrm{L}$ of sample with $57 \mu \mathrm{L}$ of the corresponding $\mathrm{H}_{2} \mathrm{O}$ buffer, followed by quenching as described above. Quenched samples were immediately digested on an immobilized pepsin column (Waters Enzymate $\mathrm{BEH}^{\mathrm{TM}}$ Pepsin $2.1 \times 30 \mathrm{~mm}$ ) at a flow rate of $100 \mu \mathrm{L} / \mathrm{min}$ using $0.1 \%$ formic acid in $\mathrm{H}_{2} \mathrm{O}$ at $15^{\circ} \mathrm{C}$. Peptic peptides were desalted for 3 min on a C18 VanGuard trap column (ACQUITY BEH C18 VanGuard $1.7 \mu \mathrm{m} 2.1 \times 5.0 \mathrm{~mm}$ ) and subsequently separated by ultra-pressure liquid chromatography using an ACQUITY BEH C18 column $(1.7 \mu \mathrm{m} 1.0 \times 100 \mathrm{~mm})$ at a flow rate of $40 \mu \mathrm{L} / \mathrm{min}$ with an acetonitrile gradient starting from $5 \%$ to $35 \%$ over 6 min, $35 \%-40 \%$ over 1 min and $40 \%-95 \%$ over $1 \mathrm{~min}$, then held at $95 \%$ for $2 \mathrm{~min}$ before returning to initial conditions. Mass spectra were obtained by a SYNAPT G2 Si High definition Mass Spectrometer equipped with an electrospray ionization (ESI) lockspray source and a low-flow probe. Data were collected in ESI positive, using $\mathrm{MS}^{\mathrm{E}}$ mode of acquisition (Waters). The capillary, cone and extraction cone voltages were set to $3 \mathrm{kV}, 30 \mathrm{~V}$ and $4 \mathrm{kV}$, respectively. Source and desolvation temperatures were set to $80^{\circ} \mathrm{C}$ and $280^{\circ} \mathrm{C}$, respectively. Trap and transfer collision energies were set to $2 \mathrm{~V}$ and $4 \mathrm{~V}$, respectively, for the low energy scans and the trap was ramped from 20-45 V for the high energy scans. Gas flow was set to $600 \mathrm{~L} / \mathrm{h}$. The mass spectrometer was calibrated with $0.5 \mathrm{M}$ sodium formate solution, and leucine enkephalin (200 pg/ $\mu \mathrm{L})$ and Glu-fibrinopeptide (100 $\mathrm{fmol} / \mu \mathrm{L})$ in Acetonitrile:Water (50:50 (v/v) + 1\% formic acid) were utilized for the lock-mass correction. Leucine enkephalin (single charge ion) and Glu-fibrinopeptide (doubly charged ion), at a mass-to-charge ratio (m/z) of $556.2771 \mathrm{Da} / \mathrm{e}$ and $785.8426 \mathrm{Da} / \mathrm{e}$, respectively, were monitored at $0.3 \mathrm{~s}$ scan times every $10 \mathrm{~s}$ for 3 scans with a mass window of $\pm 0.5 \mathrm{Da}$. The reference internal calibrant was introduced at a flow rate of $5 \mu \mathrm{L} / \mathrm{min}$ using the lock mass sprayer and the acquired spectra were automatically corrected using the two lockmasses. Argon gas was used for collision induced dissociation (CID). Mass spectra were acquired in the range of 50-2000 $\mathrm{m} / \mathrm{z}$ for $10 \mathrm{~min}$.

Peptic peptides from the non-deuterated samples with variable methionine oxidation modification were identified 
using ProteinLynx Global SERVER ${ }^{\mathrm{TM}}$ 3.0.3 (Waters). Only peptides identified with high confidence (peptide score of 7) were retained for HDX analysis. The level of deuterium uptake for each peptide was determined using the centroid of isotopic distribution in the DynamX HDX Data Analysis software (Waters). All assigned ion spectra were manually inspected and revised. The deuterium uptake for each peptide was calculated by the difference in center masses at each time point compared with the undeuterated control. The average back-exchange in our system $(\sim 30 \%)$ was measured using phosphorylase $\mathrm{B}$, but we did not correct for back exchange as our analysis compares relative deuteration between protein states. All data were derived from triplicate technical replicates. The detailed HDX-MS results are summarized in table S2 and were generated according to the recommendations by Masson et al. (50).

\section{Figures}

All figures were generated using either PyMOL (v2.5) (51) or UCSF Chimera (v1.15). Movies were made in either UCSF Chimera (v1.15) (46) or UCSF ChimeraX (v0.91) (52) and composited in Adobe Premier or Microsoft PowerPoint. To display protein in maps from 3D variance analysis (Fig. 5 and Fig. 6), the protein backbone was flexibly fitted into the illustrated map frames using Isolde (53), implemented in ChimeraX. Binding pocket volumes (fig. S4) were calculated using HOLLOW (54) and displayed using Chimera.

\section{REFERENCES AND NOTES}

1. S. P. H. Alexander, A. Christopoulos, A. P. Davenport, E. Kelly, A. Mathie, J. A. Peters, E. L. Veale, J. F. Armstrong, E. Faccenda, S. D. Harding, A. J. Pawson, J. L. Sharman, C. Southan, J. A. Davies, CGTP Collaborators, The concise guide to pharmacology 2019/2020: G protein-coupled receptors. Br. J. Pharmacol. 176, S21-S141 (2019). doi:10.1111/bph.14748 Medline

2. A. K. Shukla, Ed., G Protein-Coupled Receptors: Signaling, Trafficking and Regulation, vol. 132 of Methods in Cell Biology (Elsevier, 2016).

3. D. M. Thal, Z. Vuckovic, C. J. Draper-Joyce, Y.-L. Liang, A. Glukhova, A. Christopoulos, P. M. Sexton, Recent advances in the determination of $\mathrm{G}$ proteincoupled receptor structures. Curr. Opin. Struct. Biol. 51, 28-34 (2018). doi:10.1016/i.sbi.2018.03.002 Medline

4. C. Munk, E. Mutt, V. Isberg, L. F. Nikolajsen, J. M. Bibbe, T. Flock, M. A. Hanson, R. C. Stevens, X. Deupi, D. E. Gloriam, An online resource for GPCR structure determination and analysis. Nat. Methods 16, 151-162 (2019). doi:10.1038/s41592-018-0302-x Medline

5. J. Wang, T. Hua, Z.-J. Liu, Structural features of activated GPCR signaling complexes. Curr. Opin. Struct. Biol. 63, 82-89 (2020). doi:10.1016/j.sbi.2020.04.008 Medline

6. J. García-Nafría, C. G. Tate, Cryo-EM structures of GPCRs coupled to $G_{s}, G_{i}$ and $G_{0}$. Mol. Cell. Endocrinol. 488, 1-13 (2019). doi:10.1016/j.mce.2019.02.006 Medline

7. L. M. Wingler, R. J. Lefkowitz, Conformational basis of $\mathrm{G}$ protein-coupled receptor signaling versatility. Trends Cell Biol. 30, 736-747 (2020). doi:10.1016/j.tcb.2020.06.002 Medline

8. I. Sutkeviciute, J. P. Vilardaga, Structural insights into emergent signaling modes of G protein-coupled receptors. J. Biol. Chem. 295, 11626-11642 (2020). doi:10.1074/jbc.REV120.009348 Medline

9. W. I. Weis, B. K. Kobilka, The molecular basis of $G$ protein-coupled receptor activation. Annu. Rev. Biochem. 87, 897-919 (2018). doi:10.1146/annurevbiochem-060614-033910 Medline
10. M. Casiraghi, E. Point, A. Pozza, K. Moncoq, J. L. Banères, L. J. Catoire, NMR analysis of GPCR conformational landscapes and dynamics. Mol. Cell. Endocrinol. 484, 69-77 (2019). doi:10.1016/imce.2018.12.019 Medline

11. A. A. Pioszak, D. L. Hay, RAMPs as allosteric modulators of the calcitonin and calcitonin-like class B G protein-coupled receptors. Adv. Pharmacol. 88, 115-141 (2020). doi:10.1016/bs.apha.2020.01.001 Medline

12. A. Charles, P. Pozo-Rosich, Targeting calcitonin gene-related peptide: A new era in migraine therapy. Lancet 394, 1765-1774 (2019). doi:10.1016/S01406736(19)32504-8 Medline

13. L. M. McLatchie, N. J. Fraser, M. J. Main, A. Wise, J. Brown, N. Thompson, R. Solari, M. G. Lee, S. M. Foord, RAMPs regulate the transport and ligand specificity of the calcitonin-receptor-like receptor. Nature 393, 333-339 (1998). doi:10.1038/30666 Medline

14. Y.-L. Liang, M. Khoshouei, G. Deganutti, A. Glukhova, C. Koole, T. S. Peat, M. Radjainia, J. M. Plitzko, W. Baumeister, L. J. Miller, D. L. Hay, A. Christopoulos, C. A. Reynolds, D. Wootten, P. M. Sexton, Cryo-EM structure of the active, Gs-protein complexed, human CGRP receptor. Nature 561, 492-497 (2018). doi:10.1038/s41586-018-0535-y Medline

15. Y.-L. Liang, M. J. Belousoff, M. M. Fletcher, X. Zhang, M. Khoshouei, G. Deganutti, C. Koole, S. G. B. Furness, L. J. Miller, D. L. Hay, A. Christopoulos, C. A. Reynolds, R. Danev, D. Wootten, P. M. Sexton, Structure and dynamics of adrenomedullin receptors $A M_{1}$ and $A M_{2}$ reveal key mechanisms in the control of receptor phenotype by receptor activity-modifying proteins. ACS Pharmacol. TransI. Sci. 3 , 263-284 (2020). doi:10.1021/acsptsci.9b00080 Medline

16. Y.-L. Liang, P. Zhao, C. Draper-Joyce, J. A. Baltos, A. Glukhova, T. T. Truong, L. T. May, A. Christopoulos, D. Wootten, P. M. Sexton, S. G. B. Furness, Dominant negative $G$ proteins enhance formation and purification of agonist-GPCR-G protein complexes for structure determination. ACS Pharmacol. Transl. Sci. 1, 1220 (2018). doi:10.1021/acsptsci.8b00017 Medline

17. Y. Zhang, B. Sun, D. Feng, H. Hu, M. Chu, Q. Qu, J. T. Tarrasch, S. Li, T. Sun Kobilka, B. K. Kobilka, G. Skiniotis, Cryo-EM structure of the activated GLP-1 receptor in complex with a G protein. Nature 546, 248-253 (2017). doi:10.1038/nature22394 Medline

18. M. A. Ayoub, A. Al-Senaidy, J.-P. Pin, Receptor-G protein interaction studied by bioluminescence resonance energy transfer: Lessons from protease-activated receptor 1. Front. Endocrinol. 3, 82 (2012). doi:10.3389/fendo.2012.00082 Medline

19. O. Cevheroğlu, J. M. Becker, Ç. D. Son, GPCR-G $\alpha$ protein precoupling: Interaction between Ste2p, a yeast GPCR, and Gpalp, its Go protein, is formed before ligand binding via the Ste2p C-terminal domain and the Gpalp N-terminal domain. Biochim. Biophys. Acta Biomembr. 1859, 2435-2446 (2017). doi:10.1016/i.bbamem.2017.09.022 Medline

20. J. Zivanov, T. Nakane, B. O. Forsberg, D. Kimanius, W. J. Hagen, E. Lindahl, S. H. Scheres, New tools for automated high-resolution cryo-EM structure determination in RELION-3. elife 7, e42166 (2018). doi:10.7554/eLife.42166 Medline

21. A. Punjani, J. L. Rubinstein, D. J. Fleet, M. A. Brubaker, cryoSPARC: Algorithms for rapid unsupervised cryo-EM structure determination. Nat. Methods 14, 290-296 (2017). doi:10.1038/nmeth. 4169 Medline

22. A. Punjani, H. Zhang, D. J. Fleet, Non-uniform refinement: Adaptive regularization improves single-particle cryo-EM reconstruction. Nat. Methods 17, 1214-1221 (2019). doi:10.1038/s41592-020-00990-8 Medline

23. K. Ramlaul, C. M. Palmer, T. Nakane, C. H. S. Aylett, Mitigating local over-fitting during single particle reconstruction with SIDESPLITTER. J. Struct. Biol. 211, 107545 (2020). doi:10.1016/i.jsb.2020.107545 Medline

24. Y.-L. Liang, M. J. Belousoff, P. Zhao, C. Koole, M. M. Fletcher, T. T. Truong, V. Julita, G. Christopoulos, H. E. Xu, Y. Zhang, M. Khoshouei, A. Christopoulos, R. Danev, P. M. Sexton, D. Wootten, Toward a structural understanding of class B GPCR peptide binding and activation. Mol. Cell 77, 656-668.e5 (2020). doi:10.1016/i.molcel.2020.01.012 Medline

25. M. Dong, G. Deganutti, S. J. Piper, Y.-L. Liang, M. Khoshouei, M. J. Belousoff, K. G. Harikumar, C. A. Reynolds, A. Glukhova, S. G. B. Furness, A. Christopoulos, R. Danev, D. Wootten, P. M. Sexton, L. J. Miller, Structure and dynamics of the active Gs-coupled human secretin receptor. Nat. Commun. 11, 4137 (2020). doi:10.1038/s41467-020-17791-4 Medline 
26. S. Ma, Q. Shen, L. H. Zhao, C. Mao, X. E. Zhou, D. D. Shen, P. W. de Waal, P. Bi, C. Li, Y. Jiang, M. W. Wang, P. M. Sexton, D. Wootten, K. Melcher, Y. Zhang, H. E. Xu, Molecular basis for hormone recognition and activation of corticotropin-releasing factor receptors. Mol. Cell 77, 669-680.e4 (2020). doi:10.1016/i.molcel.2020.01.013 Medline

27. C. de Graaf, G. Song, C. Cao, Q. Zhao, M. W. Wang, B. Wu, R. C. Stevens, Extending the Structural view of class B GPCRs. Trends Biochem. Sci. 42, 946-960 (2017). doi:10.1016/i.tibs.2017.10.003 Medline

28. D. Wootten, C. A. Reynolds, K. J. Smith, J. C. Mobarec, S. G. Furness, L. J. Miller, A. Christopoulos, P. M. Sexton, Key interactions by conserved polar amino acids located at the transmembrane helical boundaries in Class B GPCRs modulate activation, effector specificity and biased signalling in the glucagon-like peptide-1 receptor. Biochem. Pharmacol. 118, 68-87 (2016). doi:10.1016/i.bcp.2016.08.015 Medline

29. S. Vohra, B. Taddese, A. C. Conner, D. R. Poyner, D. L. Hay, J. Barwell, P. J. Reeves, G. J. Upton, C. A. Reynolds, Similarity between class A and class B G-proteincoupled receptors exemplified through calcitonin gene-related peptide receptor modelling and mutagenesis studies. J. R. Soc. Interface 10, 20120846 (2013). doi:10.1098/rsif.2012.0846 Medline

30. D. Wootten, J. Simms, L. J. Miller, A. Christopoulos, P. M. Sexton, Polar transmembrane interactions drive formation of ligand-specific and signal pathway-biased family B G protein-coupled receptor conformations. Proc. Natl. Acad. Sci. U.S.A. 110, 5211-5216 (2013). doi:10.1073/pnas.1221585110 Medline

31. Y.-L. Liang, M. Khoshouei, M. Radjainia, Y. Zhang, A. Glukhova, J. Tarrasch, D. M. Thal, S. G. B. Furness, G. Christopoulos, T. Coudrat, R. Danev, W. Baumeister, L. J. Miller, A. Christopoulos, B. K. Kobilka, D. Wootten, G. Skiniotis, P. M. Sexton, Phase-plate cryo-EM structure of a class B GPCR-G-protein complex. Nature 546, 118-123 (2017). doi:10.1038/nature22327 Medline

32. X. Zhang, M. J. Belousoff, P. Zhao, A. J. Kooistra, T. T. Truong, S. Y. Ang, C. R. Underwood, T. Egebjerg, P. Šenel, G. D. Stewart, Y.-L. Liang, A. Glukhova, H. Venugopal, A. Christopoulos, S. G. B. Furness, L. J. Miller, S. Reedtz-Runge, C. J. Langmead, D. E. Gloriam, R. Danev, P. M. Sexton, D. Wootten, Differential GLP-1R binding and activation by peptide and non-peptide agonists. Mol. Cell 80, 485500.e7 (2020). doi:10.1016/j.molcel.2020.09.020 Medline

33. J. Simms, D. L. Hay, R. J. Bailey, G. Konycheva, G. Bailey, M. Wheatley, D. R. Poyner, Structure-function analysis of RAMP1 by alanine mutagenesis. Biochemistry 48, 198-205 (2009). doi:10.1021/bi801869n Medline

34. M. J. Woolley, A. C. Conner, Comparing the molecular pharmacology of CGRP and adrenomedullin. Curr. Protein Pept. Sci. 14, 358-374 (2013). doi:10.2174/13892037113149990053 Medline

35. Y. Du, N. M. Duc, S. G. F. Rasmussen, D. Hilger, X. Kubiak, L. Wang, J. Bohon, H. R. Kim, M. Wegrecki, A. Asuru, K. M. Jeong, J. Lee, M. R. Chance, D. T. Lodowski, B. K. Kobilka, K. Y. Chung, Assembly of a GPCR-G protein complex. Cell 177, 12321242.el1 (2019). doi:10.1016/i.cell.2019.04.022 Medline

36. A. Yano, Y. Takahashi, H. Moriguchi, T. Inazumi, T. Koga, A. Otaka, Y. Sugimoto, An aromatic amino acid within intracellular loop 2 of the prostaglandin EP2 receptor is a prerequisite for selective association and activation of Gas. Biochim. Biophys. Acta Mol. Cell Biol. Lipids 1862, 615-622 (2017). doi:10.1016/i.bbalip.2017.03.006 Medline

37. M. J. Woolley, J. Simms, J. C. Mobarec, C. A. Reynolds, D. R. Poyner, A. C. Conner, Understanding the molecular functions of the second extracellular loop (ECL2) of the calcitonin gene-related peptide (CGRP) receptor using a comprehensive mutagenesis approach. Mol. Cell. Endocrinol. 454, 39-49 (2017). doi:10.1016/i.mce.2017.05.034 Medline

38. J. Barwell, A. Conner, D. R. Poyner, Extracellular loops 1 and 3 and their associated transmembrane regions of the calcitonin receptor-like receptor are needed for CGRP receptor function. Biochim. Biophys. Acta Mol. Cell Res. 1813, 1906-1916 (2011). doi:10.1016/j.bbamcr.2011.06.005 Medline

39. S. A. Hjorth, C. Orskov, T. W. Schwartz, Constitutive activity of glucagon receptor mutants. Mol. Endocrinol. 12, 78-86 (1998). doi:10.1210/mend.12.1.0045 Medline

40. E. Schipani, C. B. Langman, A. M. Parfitt, G. S. Jensen, S. Kikuchi, S. W. Kooh, W. G. Cole, H. Jüppner, Constitutively activated receptors for parathyroid hormone and parathyroid hormone-related peptide in Jansen's metaphyseal chondrodysplasia. N. Engl. J. Med. 335, 708-714 (1996). doi:10.1056/NEJM199609053351004 Medline
41. C. M. Koth, J. M. Murray, S. Mukund, A. Madjidi, A. Minn, H. J. Clarke, T. Wong, V. Chiang, E. Luis, A. Estevez, J. Rondon, Y. Zhang, I. Hötzel, B. B. Allan, Molecular basis for negative regulation of the glucagon receptor. Proc. Natl. Acad. Sci. U.S.A. 109, 14393-14398 (2012). doi:10.1073/pnas.1206734109 Medline

42. L. Yang, D. Yang, C. de Graaf, A. Moeller, G. M. West, V. Dharmarajan, C. Wang, F. Y. Siu, G. Song, S. Reedtz-Runge, B. D. Pascal, B. Wu, C. S. Potter, H. Zhou, P. R. Griffin, B. Carragher, H. Yang, M.-W. Wang, R. C. Stevens, H. Jiang, Conformational states of the full-length glucagon receptor. Nat. Commun. 6, 7859 (2015). doi:10.1038/ncomms8859 Medline

43. F. Wu, L. Yang, K. Hang, M. Laursen, L. Wu, G. W. Han, Q. Ren, N. K. Roed, G. Lin, M. A. Hanson, H. Jiang, M. W. Wang, S. Reedtz-Runge, G. Song, R. C. Stevens, Fulllength human GLP-1 receptor structure without orthosteric ligands. Nat. Commun. 11, 1272 (2020). doi:10.1038/s41467-020-14934-5 Medline

44. S. Q. Zheng, E. Palovcak, J. P. Armache, K. A. Verba, Y. Cheng, D. A. Agard, MotionCor2: Anisotropic correction of beam-induced motion for improved cryoelectron microscopy. Nat. Methods 14, 331-332 (2017). doi:10.1038/nmeth.4193 Medline

45. A. Rohou, N. Grigorieff, CTFFIND4: Fast and accurate defocus estimation from electron micrographs. J. Struct. Biol. 192, 216-221 (2015). doi:10.1016/i.jsb.2015.08.008 Medline

46. E. F. Pettersen, T. D. Goddard, C. C. Huang, G. S. Couch, D. M. Greenblatt, E. C. Meng, T. E. Ferrin, UCSF Chimera-A visualization system for exploratory research and analysis. J. Comput. Chem. 25, 1605-1612 (2004). doi:10.1002/jcc.20084 Medline

47. J. C. Phillips, R. Braun, W. Wang, J. Gumbart, E. Tajkhorshid, E. Villa, C. Chipot, R. D. Skeel, L. Kalé, K. Schulten, Scalable molecular dynamics with NAMD. J. Comput. Chem. 26, 1781-1802 (2005). doi:10.1002/icc.20289 Medline

48. P. Emsley, B. Lohkamp, W. G. Scott, K. Cowtan, Features and development of Coot. Acta Cryst. D66, 486-501 (2010). doi:10.1107/S0907444910007493 Medline

49. P. V. Afonine, B. K. Poon, R. J. Read, O. V. Sobolev, T. C. Terwilliger, A. Urzhumtsev, P. D. Adams, Real-space refinement in PHENIX for cryo-EM and crystallography. Acta Cryst. D74, 531-544 (2018). doi:10.1107/S2059798318006551 Medline

50. G. R. Masson, J. E. Burke, N. G. Ahn, G. S. Anand, C. Borchers, S. Brier, G. M. BouAssaf, J. R. Engen, S. W. Englander, J. Faber, R. Garlish, P. R. Griffin, M. L. Gross, M. Guttman, Y. Hamuro, A. J. R. Heck, D. Houde, R. E. lacob, T. J. D. Jørgensen, I. A. Kaltashov, J. P. Klinman, L. Konermann, P. Man, L. Mayne, B. D. Pascal, D. Reichmann, M. Skehel, J. Snijder, T. S. Strutzenberg, E. S. Underbakke, C. Wagner, T. E. Wales, B. T. Walters, D. D. Weis, D. J. Wilson, P. L. Wintrode, Z. Zhang, J. Zheng, D. C. Schriemer, K. D. Rand, Recommendations for performing, interpreting and reporting hydrogen deuterium exchange mass spectrometry (HDX-MS) experiments. Nat. Methods 16, 595-602 (2019). doi:10.1038/s41592019-0459-y Medline

51. Schrodinger, LLC., The PyMOL Molecular Graphics System, version 1.3r1 (2010).

52. E. F. Pettersen, T. D. Goddard, C. C. Huang, E. C. Meng, G. S. Couch, T. I. Croll, J. H. Morris, T. E. Ferrin, UCSF ChimeraX: Structure visualization for researchers, educators, and developers. Protein Sci. 30, 70-82 (2021). doi:10.1002/pro.3943 Medline

53. T. I. Croll, ISOLDE: A physically realistic environment for model building into lowresolution electron-density maps. Acta Cryst. D74, 519-530 (2018) doi:10.1107/S2059798318002425 Medline

54. B. K. Ho, F. Gruswitz, HOLLOW: Generating accurate representations of channel and interior surfaces in molecular structures. BMC Struct. Biol. 8, 49 (2008). doi:10.1186/1472-6807-8-49 Medline

\section{ACKNOWLEDGMENTS}

The authors would like to thank Caryn Hepburn for assistance with preparation and analysis of HDX-MS samples and Daniel Gough for project support for D.J.G. Funding: The work was supported by the Monash University Ramaciotti Centre for Cryo-Electron Microscopy, the Monash MASSIVE high-performance computing facility, MIPS seed funding to T.M.J., the Australian Research Council (ARC) Centre grant (IC200100052) and ARC Discovery Project (DP210101504), the National Health and Medical Research Council of Australia (NHMRC) project grants (1120919 and 1159006) and NHMRC program grant (1150083). P.M.S. is an NHMRC Senior Principal Research Fellows and D.W. is an NHMRC Senior Research Fellow. T.M.J. is a Victoria Endowment for Science Knowledge and 
Innovation fellow. R.D. was supported by Takeda Science Foundation 2019 Medical Research Grant and Japan Science and Technology Agency PRESTO (18069571), K.L. was supported by an Australian Research Council Future Fellowship (FT160100075). Author contributions: T.M.J. and D.J.G. performed the HDX-MS experiments. S.J.P., J.C., and Y.L.L. expressed and purified receptor complexes. R.D. performed cryo-sample preparation and imaging to acquire EM data. M.J.B. processed the EM data and performed EM map calculations,

including 3D multivariate analysis, built the protein models for consensus maps and performed refinement. S.J.P. cross-checked the atomic models, and built protein models into the 3D variance data. T.M.J., M.J.B., S.J.P., and D.J.G. assisted with data interpretation, figure and manuscript preparation. All authors reviewed and edited the manuscript; A.C., P.M.S., D.W. and D.L.H. designed the project, and interpreted data. P.M.S., D.W., K.L, K.J.G. supervised the project. P.M.S. and D.W. generated figures and wrote the manuscript. Competing interests: D.L.H. is on the scientific advisory board of Amgen, all other authors declare no competing interests. Data and materials availability: All relevant data are available from the authors and/or included in the manuscript or the supplementary materials. Atomic coordinates and the cryo-EM density map have been deposited in the Protein Data Bank (PDB) under accession numbers 7KNT (apo) and 7KNU (CGRP-bound), and the Electron Microscopy Data Bank (EMDB) accession numbers EMD-22962 (apo) and EMD-22963 (CGRP-bound). All constructs used in the study are available from the authors upon reasonable request.

\section{SUPPLEMENTARY MATERIALS}

science.sciencemag.org/cgi/content/full/science.abf7258/DC1

Figs. S1 to S10

Tables S1 and S2

MDAR Reproducibility Checklist

Movies S1 to S4

Data S1

15 November 2020; accepted 11 February 2021

Published online 18 February 2021

10.1126/science.abf7258 
A
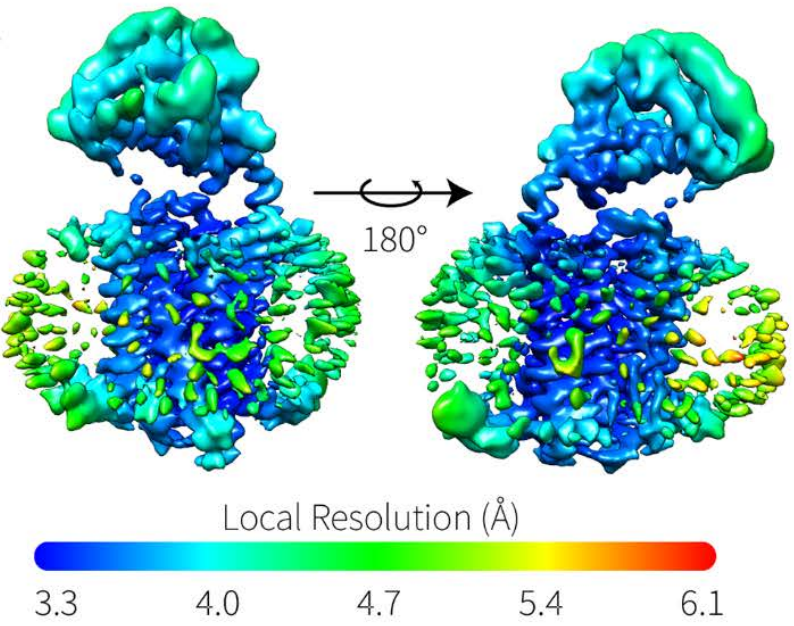

C

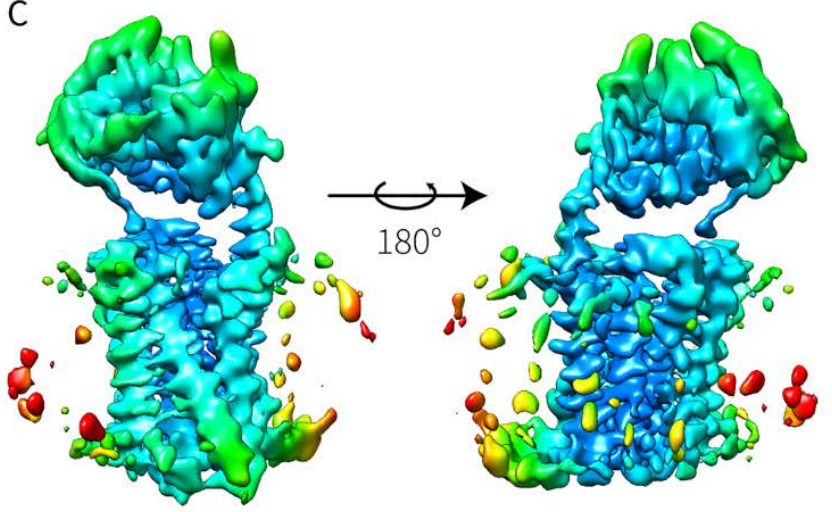

B
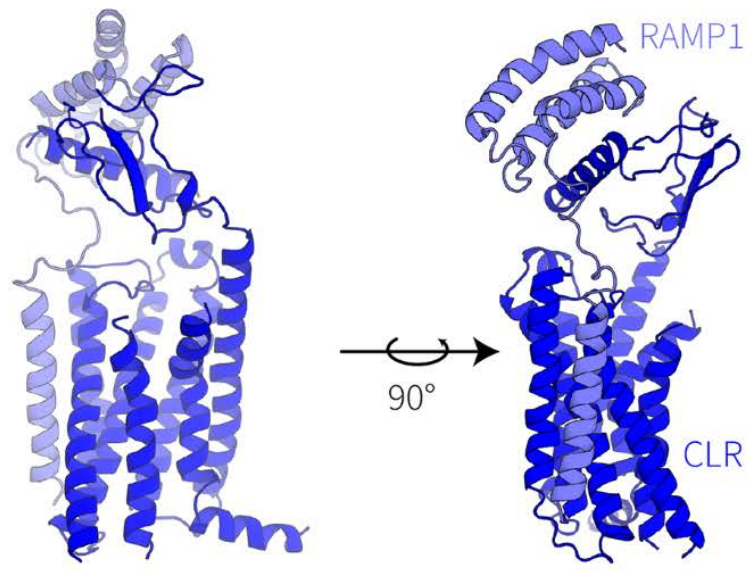

D

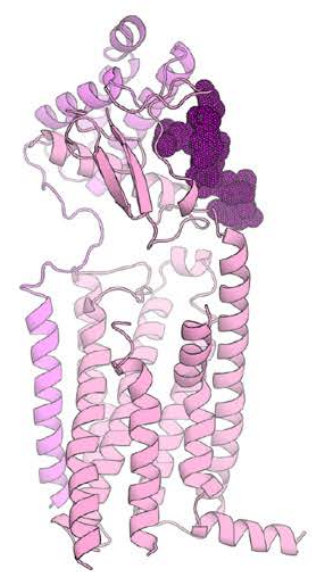

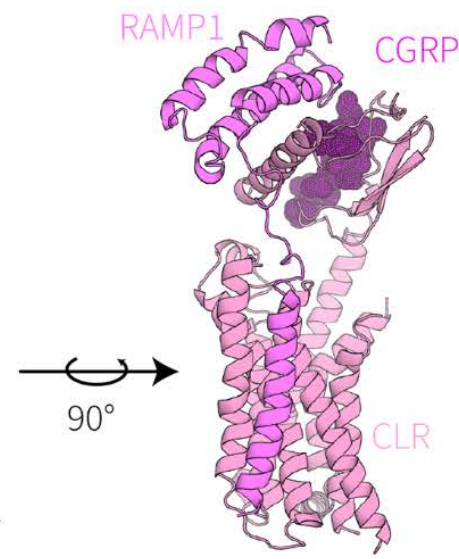

Fig. 1. Cryo-EM density map and molecular model of apo (A, B) and CGRP-bound (C, D) CGRP receptors. (A and C) Cryo-EM maps colored according to local resolution from highest resolution (dark blue) through to lowest resolution (red). (B) Model of the apo CGRP receptor, comprising RAMP1 (light blue) and CLR (medium blue) displayed in ribbon format. (D) Model of the CGRP-bound CGRP receptor, comprising RAMP1 (dark pink), CLR (light pink) in ribbon format and the $C$ terminus of CGRP (residues 27-37) displayed in space fill format. 
A
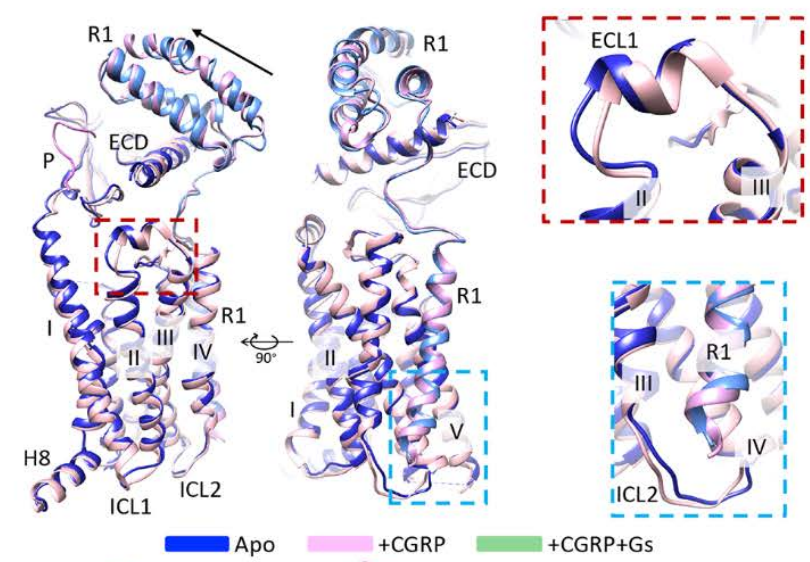

B
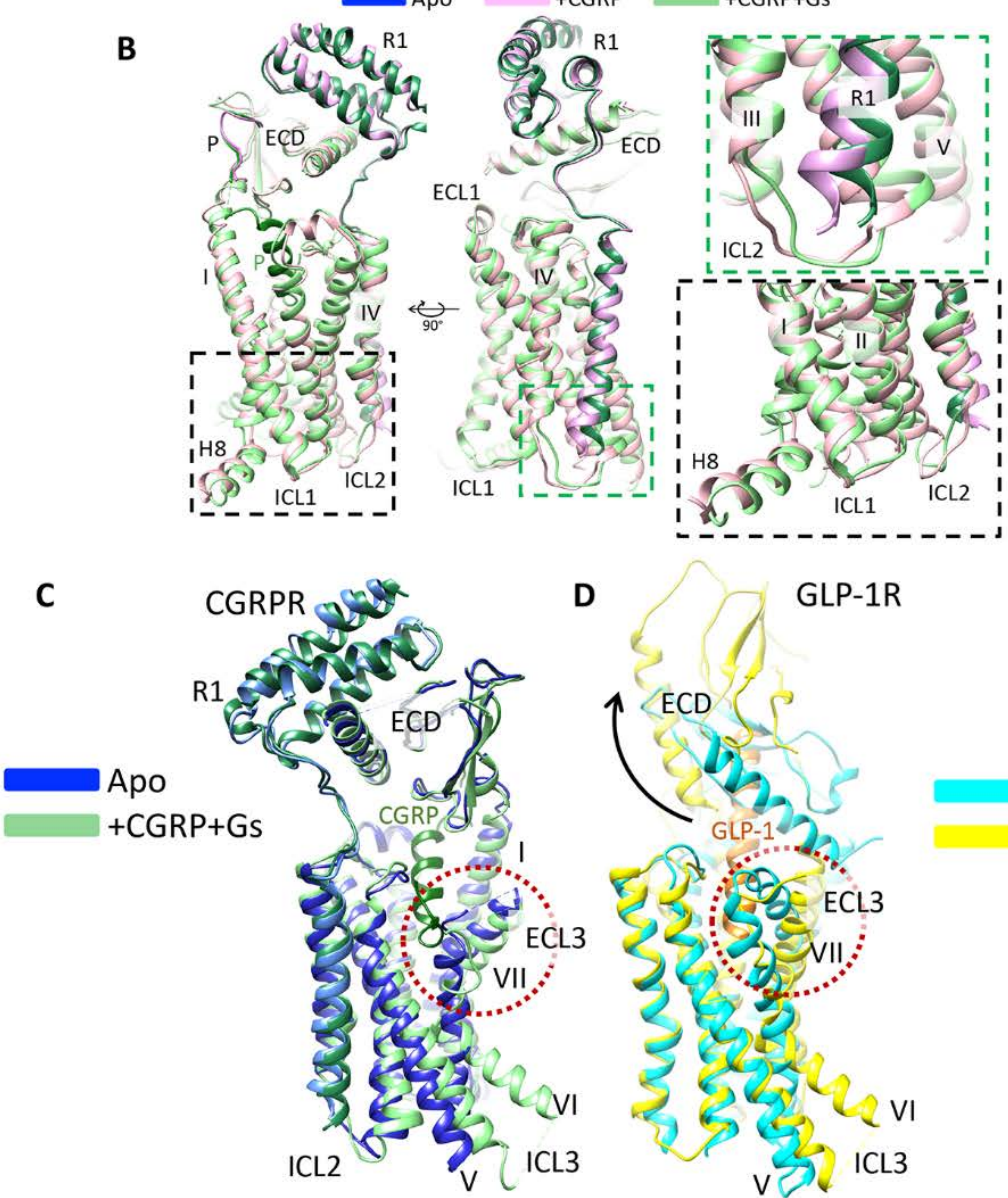

D GLP-1R

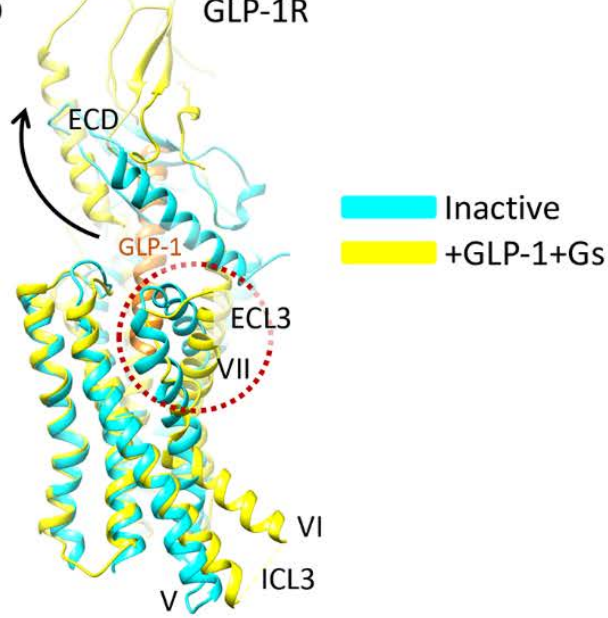

Fig. 2. Comparison of the apo, CGRP-bound and fully active, Gs-bound complex of the CGRP receptor. (A) Comparison of the backbone structure of the consensus apo (medium blue) and CGRP-bound (pink) receptors displayed in ribbon format. (B) Comparison of the backbone structure of the consensus CGRPbound (pink) and fully active CGRP-bound, Gs-bound (green) receptors, displayed in ribbon format. The G proteins are omitted for clarity. Only the C-terminal 27-37 amino acids of the peptide were resolved in the CGRP-bound structure. The colored boxed regions are enlarged in the insets. (C and D) The CGRPR (C) (apo, medium blue ribbon; CGRP (dark green)-bound active CGRPR complex, green ribbon) and GLP-1R (D) (light blue ribbon, inactive receptor; GLP-1 (orange ribbon)-bound active GLP-1R complex, yellow ribbon) undergo distinct conformational rearrangement of the extracellular face of the receptor and ECD upon agonist peptide binding but display conserved reorganization of the intracellular face of the receptor upon Gs protein binding. The distinct conformations of ECL3 in the apo/inactive and active structures is highlighted by the dashed red circle. The G proteins are omitted for clarity. Membrane helices are numbered with Roman numerals. ECD, extracellular domain of the GPCR component. ECL, extracellular loop. ICL, intracellular loop. P, peptide. R1, RAMP1. 


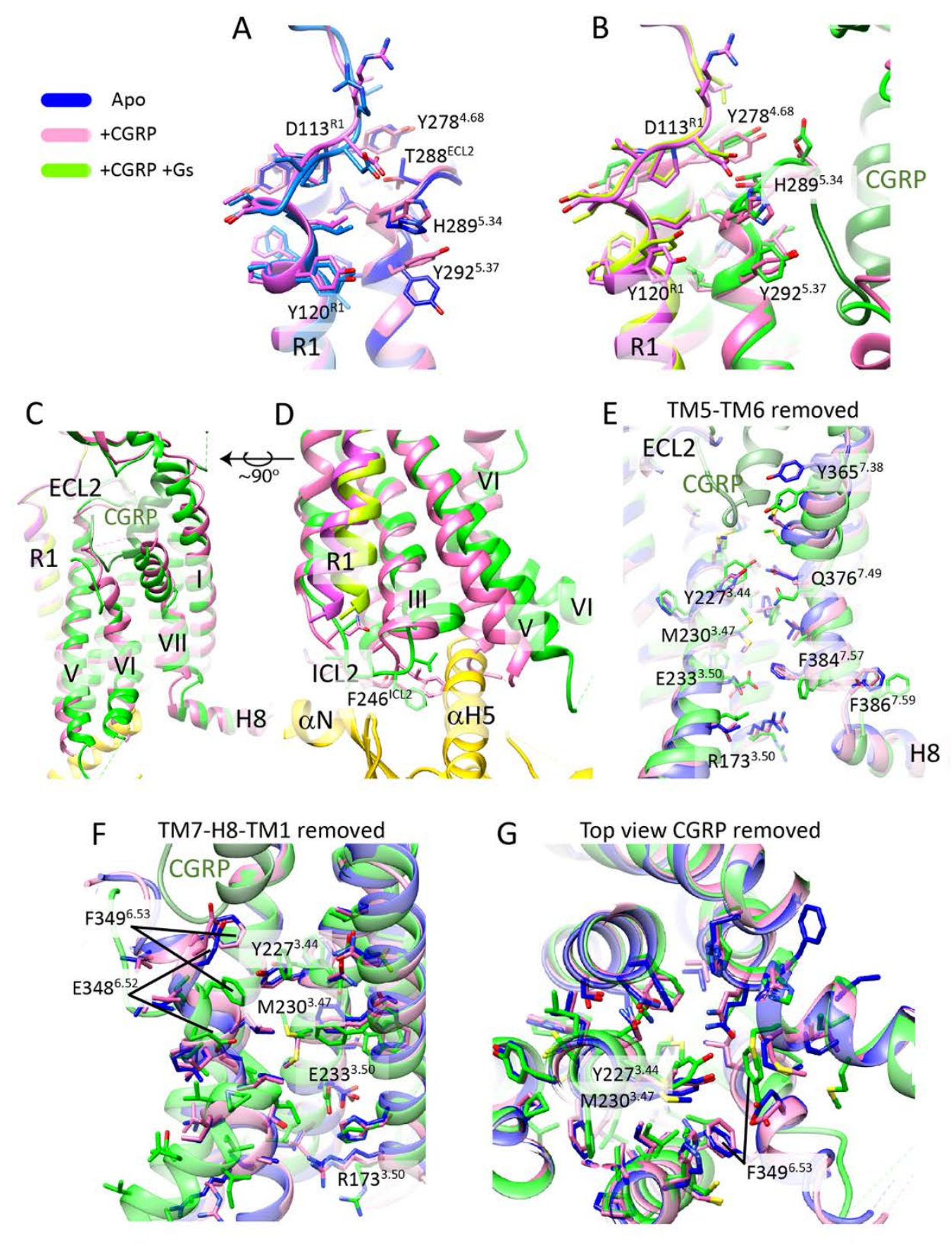

Fig. 3. Gs recruitment is required for large conformational changes in peptide-bound CGRPR. (A and B) CGRP binding is associated with subtle changes at the top of TM5 and between RAMP1 (R1) and ECL2 (A) that are not further altered by G protein recruitment (B). (C and D) G protein interaction induces changes to the location of the top of TM1, ECL2 and ECL3 that are linked to large conformational changes in base of the receptor, particularly the bottom of TM3, TM5 and TM6, along with the bottom of the RAMP1 TM helix that are required to accommodate $G$ s binding. ( $E$ to $G$ ) Key conserved class B1 GPCR residues in the core and base of the receptor undergo large scale conformational rearrangement in the $G$ protein-bound receptor, but limited change in the orientation of these sidechains between the apo and CGRP-bound receptors. Structures are displayed in ribbon format with key sidechains displayed in $\mathrm{x}$-stick format colored by heteroatom with backbone colored blue for the apo receptor, pink for the CGRP-bound receptor and green for the CGRP-bound, Gs protein-bound receptor. TM helices are labeled with Roman numerals. ECL, extracellular loop. ICL, intracellular loop. 


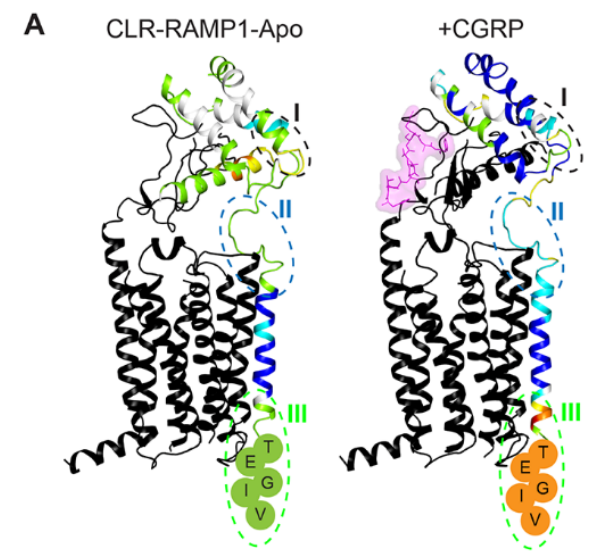

B CLR-RAMP1-Apo +CGRP
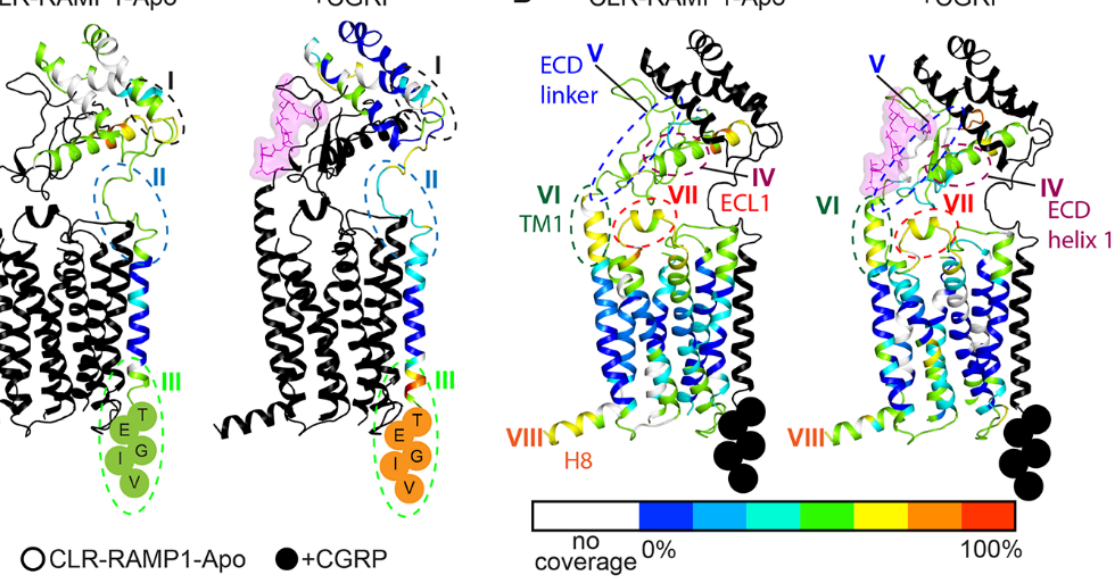

+ CGRP
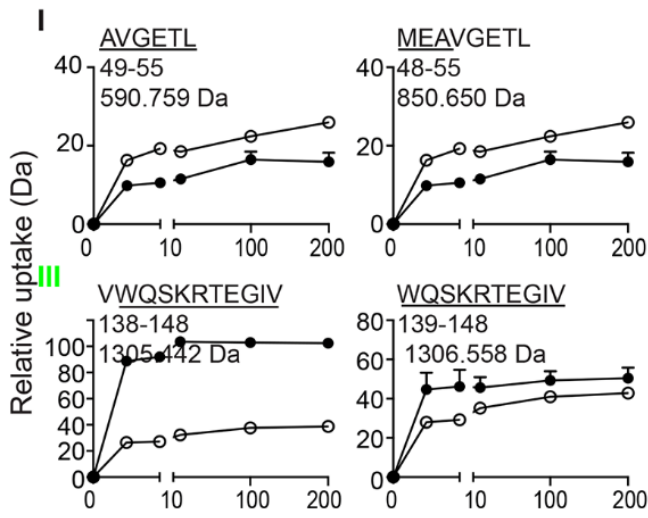

II RAVRDPPGSIL VRDPPGSIL
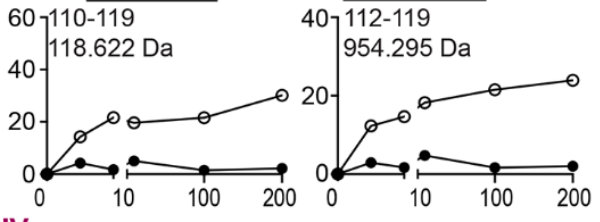

WQSKRTEGIV

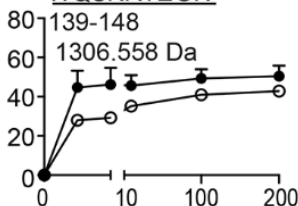

IV LGVTRNKIM

$60-60734-42$

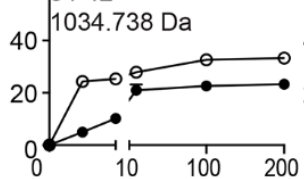

V QDFDPSEKVTKICDQDGNW FQDFDPSE
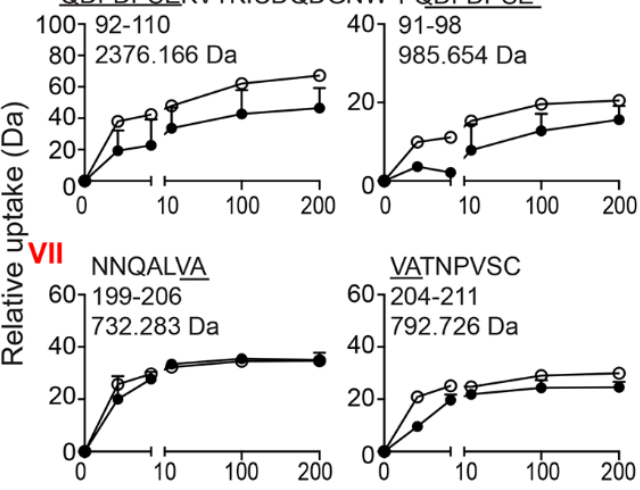

VI KVKTALNL
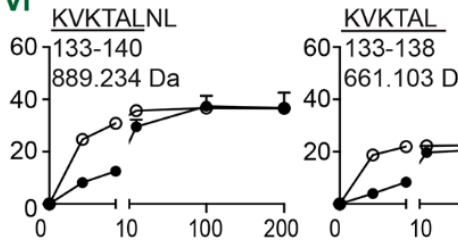

40

661.103
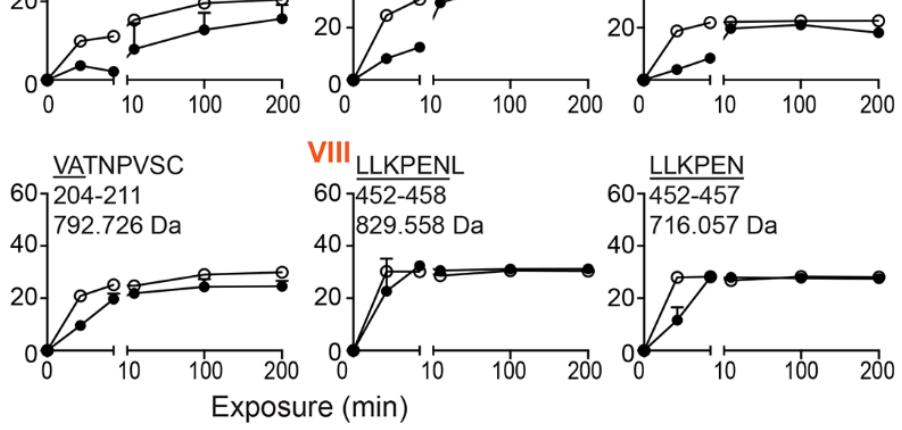

LLKPEN

$607452-457$

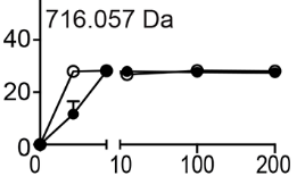

Exposure (min)

Fig. 4. Conformational dynamics of apo and CGRP-bound CGRPRs assessed by HDX-MS. (A and B) Structures of the receptors are displayed in ribbon format, colored according to the percentage of deuterium incorporation for each peptide after 200 min, illustrating deuterium uptake for RAMP1 (A) or CLR (B) colored from lowest incorporation (dark blue) to highest incorporation (red). Residues for the RAMP-1 C terminus that are not resolved in the cryo-EM structure are shown as circled amino acids. Data are normalized to the difference of deuteration between unlabeled samples at $\mathrm{t} O$ and the maximum deuterium uptake. (C) The change in deuterium incorporation over time is displayed for select peptic digest peptides with the location of the peptides displayed on the structures (dashed ovals) labeled from (I) to (VIII). The graphs (C) display the mean of measurements from independent preparations (performed in triplicate repeats); Apo $(n=1)$, CGRP-bound $(n=2)$, error bars are S.D. from the mean of independent experiments. Selected nested peptides are underlined. 

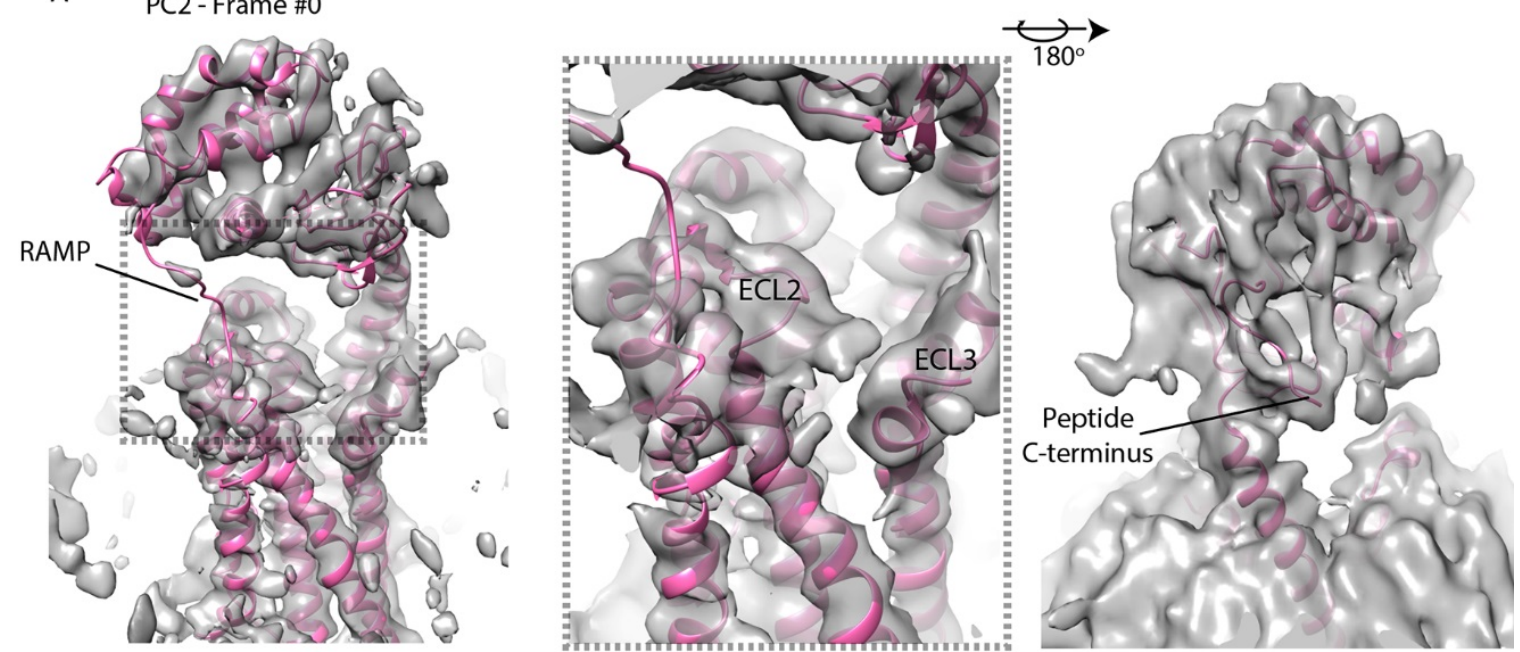

B PC2 - Frame \#19
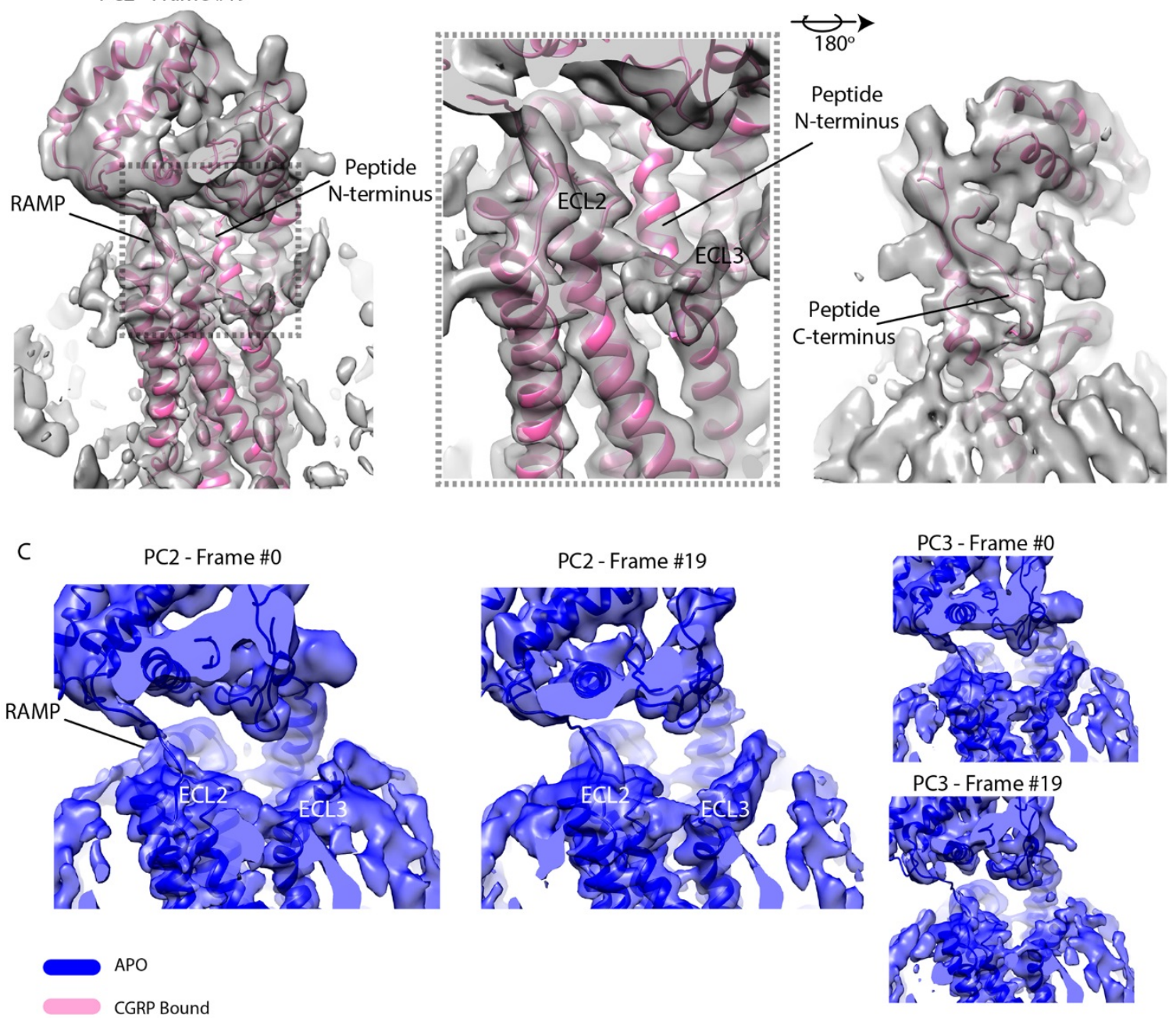

Fig. 5. 3D variance analysis of the cryo-EM data reveals transient interaction of the peptide $N$ terminus with the receptor core. Conformational variance data were mapped to 3 principal components (PC1-PC3). (A) Frame \#0 of PC2 reveals density for the peptide $\mathrm{C}$ terminus in the CGRP-bound structure, but no density for the $\mathrm{N}$ terminus. (B) Frame \#19 of PC2 reveals opening of the top of TM6-ECL3-TM7 and density for the peptide $\mathrm{N}$ terminus, as well as the peptide $\mathrm{C}$ terminus. Middle panels display an enlarged view of the TM core. (C) Start and end frames from PC2 and PC3 of the apo receptor demonstrating absence of density for peptide and limited conformational change to ECL3. Electron density maps are displayed in transparent surface representation (blue, apo; grey, CGRP-bound) with the backbone structure of the receptor complexes fit into each of the density maps displayed in ribbon format (apo, blue; CGRP-bound, pink). 
A
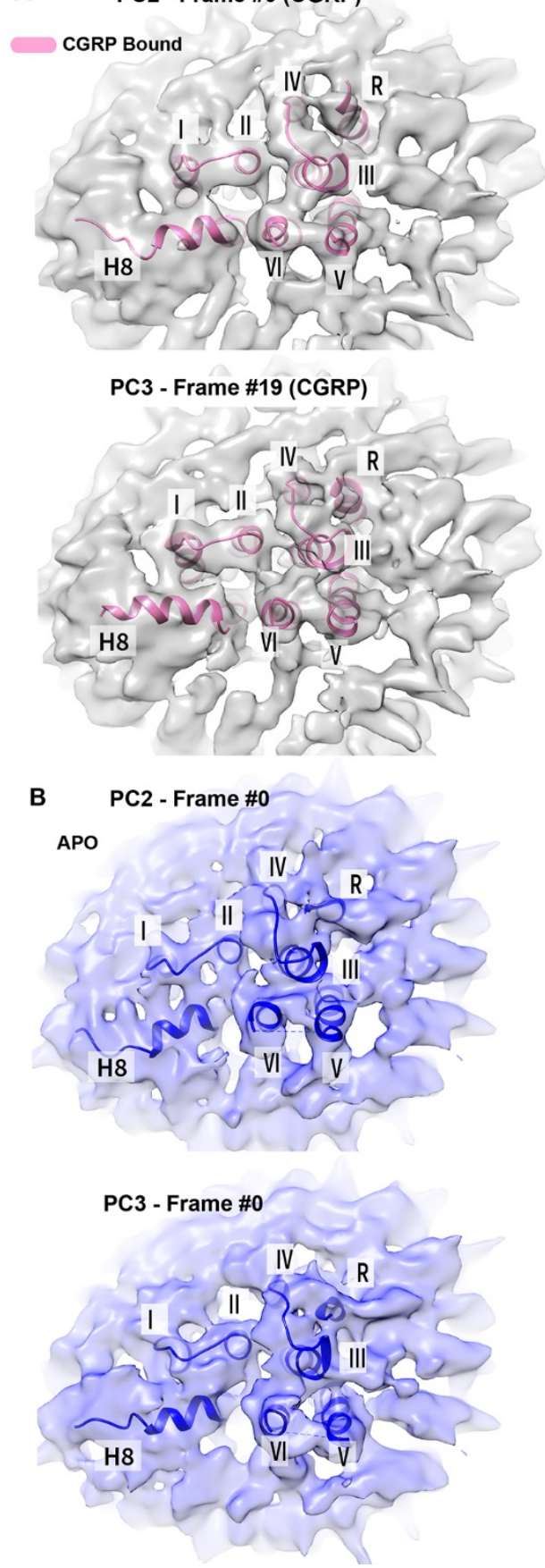

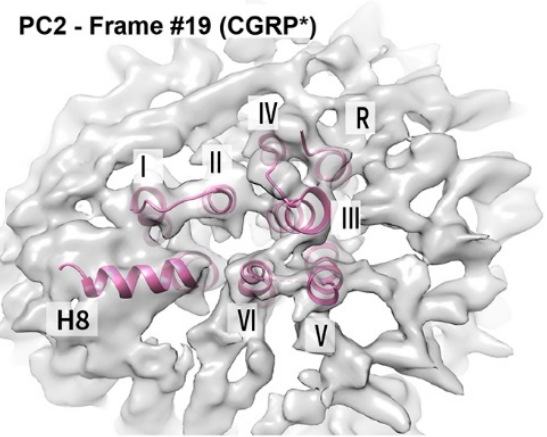

PC3 - Frame \#0 (CGRP*)
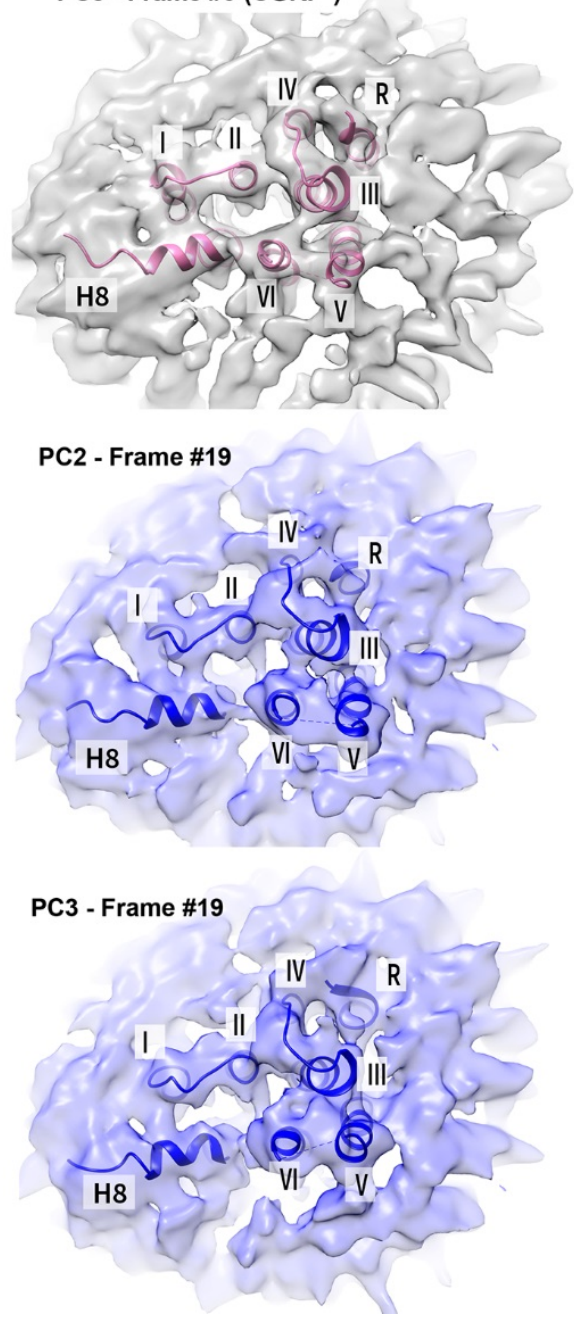

Fig. 6. 3D variance analysis of the base of the apo and CGRP-bound peptide complexes reveals changes to the dynamics of the receptor when the peptide $\mathrm{N}$ terminus is present in the maps. (A) Start and end conformations of PC2 and PC3 for the CGRP-bound receptor with cryo-EM density shown in transparent grey surface representation and protein backbone in pink ribbon. The frames where the peptide $\mathrm{N}$ terminus were visible are denoted by $\left(^{*}\right)$. (B) Start and end conformations of PC2 and PC3 of the apo structure with cryoEM density displayed in transparent blue surface representation and protein backbone in blue. CLR helices are labeled with Roman numerals. R, RAMP TM helix. H8, CLR helix 8. 


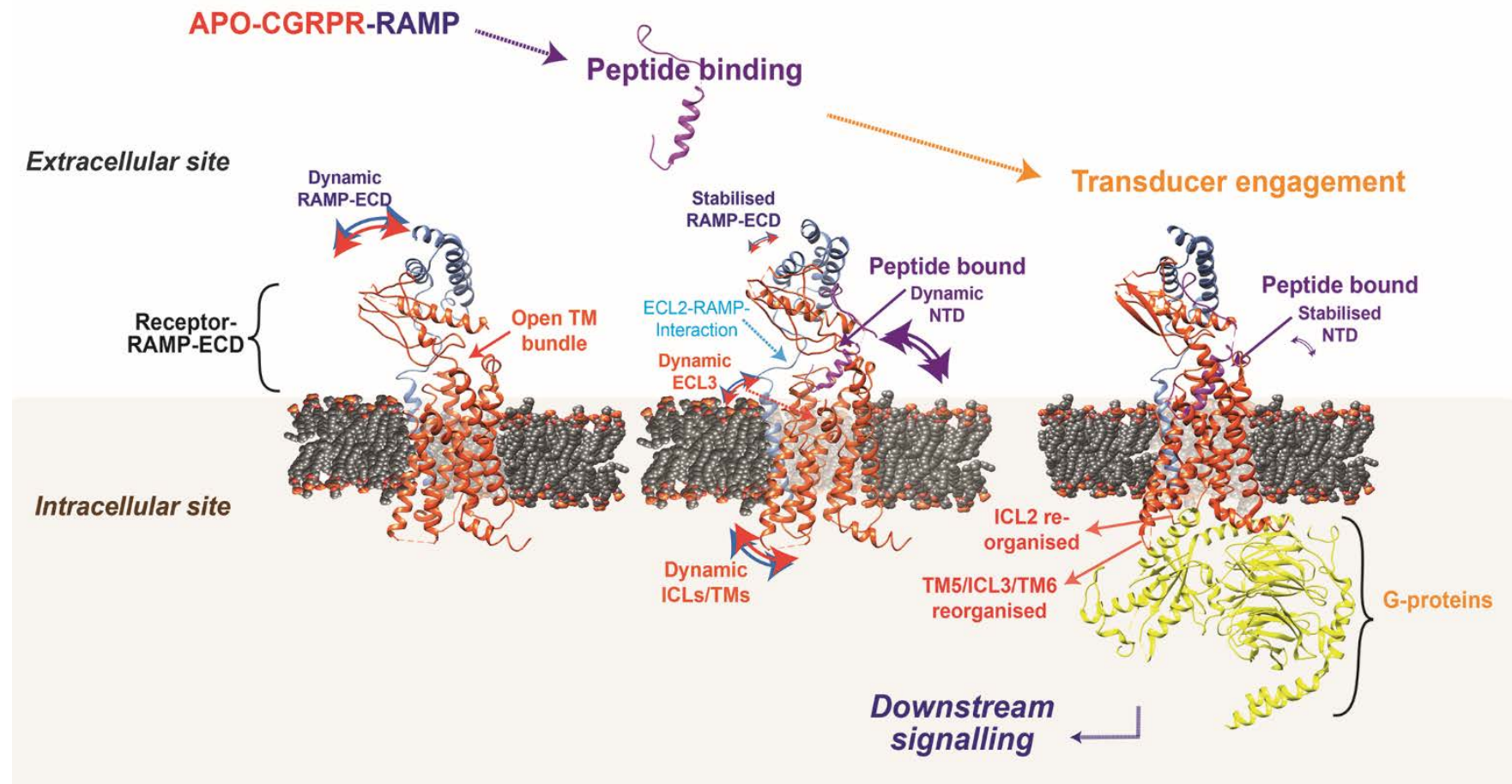

Fig. 7. Overview of the peptide binding and activation process for the CGRPR. The apo state of the receptor shows a relatively open TM bundle and dynamic ECD that can facilitate peptide binding (left). Upon CGRP binding, the RAMP-ECD stabilizes and facilitates interactions between RAMP and ECL2 of receptor, while the peptide $\mathrm{N}$ terminus remains highly dynamic (middle). Intracellular loops remain dynamic and undergo conformational changes to enable Gs binding. In the fully active, Gs-bound conformation, TM5 and TM6 undergo shifts with a kink in the bottom of TM6 to enable Gs engagement with additional conformational changes propagated within TM1, TM7 and ECL2 that stabilize the peptide $\mathrm{N}$ terminus in the binding pocket (right). NTD, CGRP N-terminal domain. 